Published in final edited form as:

J Am Chem Soc. 2018 June 13; 140(23): 7267-7281. doi:10.1021/jacs.8b03546.

\title{
Mechanism of Ti-Catalyzed Oxidative Nitrene Transfer in [2 + 2 + 1] Pyrrole Synthesis from Alkynes and Azobenzene
}

\author{
Zachary W. Davis-Gilbert $^{\dagger}$, Xuelan Wen $^{\dagger}$, Jason D. Goodpaster ${ }^{\star}$, and lan A. Tonks ${ }^{\star}$ \\ Department of Chemistry, University of Minnesota - Twin Cities, Minneapolis, Minnesota 55455, \\ United States
}

\begin{abstract}
A combined computational and experimental study on the mechanism of Ti-catalyzed formal [2 $+2+1$ ] pyrrole synthesis from alkynes and aryl diazenes is reported. This reaction proceeds through a formally $\mathrm{Ti}^{\mathrm{II}} / \mathrm{Ti}^{\mathrm{IV}}$ redox catalytic cycle as determined by natural bond orbital (NBO) and intrinsic bond orbital (IBO) analysis. Kinetic analysis of the reaction of internal alkynes with azobenzene reveals a complex equilibrium involving $\mathrm{Ti}=\mathrm{NPh}$ monomer/dimer equilibrium and $\mathrm{Ti}=\mathrm{NPh}+$ alkyne $[2+2]$ cycloaddition equilibrium along with azobenzene and pyridine inhibition equilibria prior to rate-determining second alkyne insertion. Computations support this kinetic analysis, provide insights into the structure of the active species in catalysis and the roles of solvent, and provide a new mechanism for regeneration of the Ti imido catalyst via disproportionation. Reductive elimination from a 6-membered azatitanacyclohexadiene species to generate pyrrole-bound $\mathrm{Ti}^{\mathrm{II}}$ is surprisingly facile and occurs through a unique electrocyclic reductive elimination pathway similar to a Nazarov cyclization. The resulting $\mathrm{Ti}^{\mathrm{II}}$ species are stabilized through backbonding into the $\pi^{*}$ of the pyrrole framework, although solvent effects also significantly stabilize free $\mathrm{Ti}^{\mathrm{II}}$ species that are required for pyrrole loss and catalytic turnover. Further computational and kinetic analysis reveals that in complex reactions with unysmmetric alkynes the resulting pyrrole regioselectivity is driven primarily by steric effects for terminal alkynes and inductive effects for internal alkynes.
\end{abstract}

\section{Graphical Abstract}

\footnotetext{
*Corresponding Authors: jgoodpas@umn.edu; itonks@umn.edu.

$\dagger$ Author Contributions

Z.W.D.-G. and X.W. contributed equally. All authors have given approval to the final version of the manuscript.

Supporting Information

The Supporting Information is available free of charge on the ACS Publications website at DOI: 10.1021/jacs.8b03546.

Full experimental, kinetic, and computational details (PDF)

The authors declare no competing financial interest.
} 


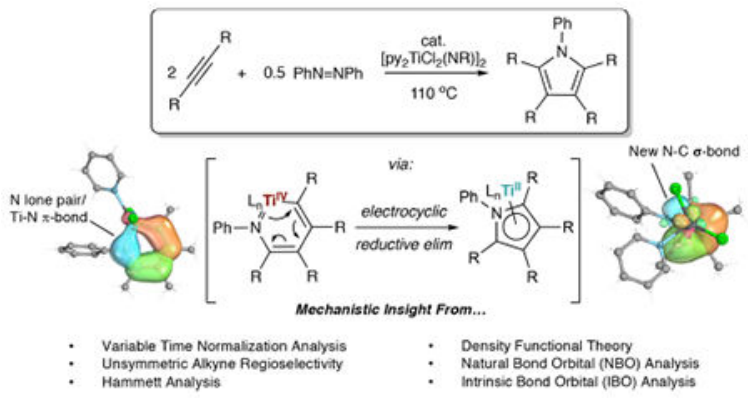

\section{INTRODUCTION}

Ti is an ideal metal for sustainable catalysis - earth abundant, environmentally benign, and easily recycled. ${ }^{1,2}$ Considering these properties, Ti catalysis is underutilized in organic method development compared to the earth-abundant first-row late transition metals ( $\mathrm{Fe}, \mathrm{Co}$, Ni). ${ }^{3-5}$ Two significant challenges in designing early transition metal catalyzed reactions are the oxophilicty of the metals and the thermodynamic stability of their highest oxidation states. In fact, Ti-catalyzed reactions involving a formal oxidation state change at the metal center (i.e., $\mathrm{Ti}^{\mathrm{II}} / \mathrm{Ti}^{\mathrm{IV}}$ ) are quite rare. ${ }^{5}$

We recently reported a Ti-catalyzed oxidative nitrene-transfer reaction that we speculated proceeds through a formally $\mathrm{Ti}^{\mathrm{II}} / \mathrm{Ti}^{\mathrm{IV}}$ catalytic cycle: the $[2+2+1]$ coupling of alkynes with diazenes to yield multisubstituted pyrroles. ${ }^{6}$ In our initial report, we proposed the mechanism shown in Figure 1: first, a Ti imido complex 1 undergoes [2 + 2] cycloaddition with an alkyne to form an azatitanacyclobutene 2 , identical to the first step of Ti-catalyzed alkyne hydroamination. ${ }^{7-9} \mathrm{Next}, \mathbf{2}$ inserts a second equivalent of alkyne to yield an azatitanacyclohexadiene 3 , which then undergoes reductive $\mathrm{C}-\mathrm{N}$ coupling to yield the pyrrole product and a $\mathrm{Ti}^{\mathrm{II}}$ species $\mathbf{4}$. Compound $\mathbf{4}$ could be reoxidized via coordination of azobenzene to form an $\eta^{2}$-hydrazido complex $\mathbf{5}$, which disproportionates to regenerate $\mathbf{1}$ and 0.5 equiv of azobenzene. Previous computational work by Wang ${ }^{10}$ confirmed the feasibility of this overall mechanistic picture through DFT calculations at the M06-L/6-311+ $+\mathrm{G}(\mathrm{d}, \mathrm{p}) / \mathrm{PCM}$ level of theory with geometries obtained in the gas phase at the B3LYP/ 6-31G(d,p) level of theory. Wang suggested that the mechanism proceeds through an unconventional elimination pathway that requires azobenzene coordination to release pyrrole, ostensibly avoiding discrete formally $\mathrm{Ti}^{\mathrm{II}}$ intermediates.

We are interested in developing a deeper experimental and theoretical understanding of the mechanism of this reaction in order to design new Ti-catalyzed nitrene-transfer reactions and further understand the requirements for catalytic turnover in low-valent early transition metal catalyzed processes. In particular, we are interested in understanding (1) the structure of the active species in catalysis and the role of catalyst structure in reactivity; (2) the kinetic interplay between the two steps involving alkyne cycloaddition and insertion; (3) how and why $\mathrm{C}-\mathrm{N}$ reductive elimination occurs; and (4) the role of azobenzene in $\mathrm{C}-\mathrm{N}$ reductive elimination and catalyst reoxidation. 
Herein, we report a detailed kinetic and computational study on the Ti-catalyzed formal [2 $+2+1]$ pyrrole synthesis. The main kinetic manifold of the reaction involves two equilibria, a Ti imido monomer/dimer equilibrium followed by a [2 +2$]$ alkyne/Ti imido cycloaddition equilibrium. Geometry optimization of intermediates in solvent turns out to be critical to uncovering several important details of the catalytic cycle. Additionally, we perform an exhaustive DFT analysis to determine which ligands are active during the catalytic cycle and find that coordinatively unsaturated complexes have the lowest transition-state barriers. By using these geometries and a combination of intrinsically bonding orbitals (IBOs) $)^{11,12}$ and natural bond orbitals (NBOs), ${ }^{13}$ we show that this reaction proceeds through a true reductive elimination pathway where discrete "Ti $\mathrm{Ti}^{\mathrm{II}}$ "-like species are present. NBOs have previously been used successfully in Ti compounds to describe bonding in Ti-imido complexes. ${ }^{7 \mathrm{~b}}$ This reductive elimination occurs via a surprising electrocyclic pathway similar to the Nazarov cyclization. The resulting $\mathrm{Ti}^{\mathrm{II}}$ pyrrole species is stabilized through backbonding into the pyrrole $\pi^{*}$ system, but stabilizing solvent interactions also allow for facile pyrrole dissociation. This mechanistic knowledge has also been extended into a combined computational and physical organic study of the stereoelectronic effects on the regioselectivity of unsymmetrical alkyne couplings, revealing that sterics predominantly control the selectivity of terminal alkyne reactions while inductive effects dominate for internal unsymmetrical alkynes such as phenylpropyne.

\section{METHODS}

\subsection{Experimental Methods}

All air- and moisture-sensitive compounds were manipulated in a glovebox under a nitrogen atmosphere. Solvents for air- and moisture-sensitive reactions were vacuum transferred from sodium benzophenone ketyl $\left(\mathrm{C}_{6} \mathrm{D}_{6}\right)$ or $\mathrm{CaH}_{2}\left(\mathrm{CDCl}_{3}, \mathrm{C}_{6} \mathrm{D}_{12}, \mathrm{C}_{7} \mathrm{D}_{8}\right)$ or predried on a Vacuum Atmospheres solvent purification system (hexanes, toluene, benzene, THF, $\mathrm{Et}_{2} \mathrm{O}$, DCM, and TFT). Solvents were stored over $\mathrm{CaH}_{2}$ and filtered through dry basic alumina before use. Azobenzene was purchased from TCI America (100 g). Commercial azobenzene is typically contaminated with $0-5 \%$ methanol and nitrobenzene; flash chromatography using hexanes and grinding the isolated product in a mortar and pestle before drying in vacuo yields analytically pure azobenzene. $\mathrm{C}_{6} \mathrm{D}_{5} \mathrm{Br}$ was prepared following the literature procedure. ${ }^{14}\left[\mathrm{py}_{2} \mathrm{TiCl}_{2} \mathrm{~N}^{t} \mathrm{Bu}\right]_{2}$ and $\mathrm{py}_{3} \mathrm{TiCl}_{2} \mathrm{~N}^{t} \mathrm{Bu}$ were prepared according to the literature procedure. ${ }^{15}$ All liquid alkynes were freeze-pump-thawed three times, brought into the glovebox, and passed through activated basic alumina before being stored at $-35^{\circ} \mathrm{C} .{ }^{1} \mathrm{H}$, ${ }^{13} \mathrm{C},{ }^{15} \mathrm{~N}, \mathrm{HMBC}, \mathrm{HSQC}, \mathrm{NOE}$, and NoD NMR spectra were recorded on Varian INOVA $500 \mathrm{MHz}$, Bruker Avance III $500 \mathrm{MHz}$, Bruker Avance III HD $500 \mathrm{MHz}$, or Bruker Avance $400 \mathrm{MHz}$ spectrometers. Chemical shifts are reported with respect to residual protio-solvent impurity for ${ }^{1} \mathrm{H}$ (s, $7.16 \mathrm{ppm}$ for $\mathrm{C}_{6} \mathrm{D}_{5} \mathrm{H} ; \mathrm{s}, 7.27$ for ppm of $\mathrm{CHCl}_{3}$ ), solvent carbons for ${ }^{13} \mathrm{C}$ $\left(\mathrm{t}, 128.39 \mathrm{ppm}\right.$ for $\mathrm{C}_{6} \mathrm{D}_{6} ; \mathrm{t}, 77.16 \mathrm{ppm}$ for $\mathrm{CDCl}_{3}$ ), referenced to tetrachloroethane (s, 5.53 $\mathrm{ppm}$ ) or trimethoxybenzene (s, $6.02 \mathrm{ppm}$ ) in $\mathrm{C}_{6} \mathrm{D}_{5} \mathrm{Br}$. Full experimental details and kinetic traces are available in the Supporting Information. 


\subsection{Computational Methods}

Geometry optimizations were performed using the Gaussian 09 program version $\mathrm{d} 01 .{ }^{16}$

Unless otherwise noted, all calculations were formed using the M06 functional, ${ }^{17}$ the $6-311 \mathrm{G}(\mathrm{d}, \mathrm{p})$ basis set, ${ }^{18}$ the ultrafine grid, and the SMD solvation mode ${ }^{19}$ in the experimentally used solvent $\mathrm{PhCF}_{3}(\varepsilon=9.18)$. Calculations performed for symmetric alkynes used the superfine grid. All geometries were characterized by frequency analysis calculations to be minima (without imaginary frequency) or transition states (having only one imaginary frequency). The refined energies were corrected to free energies at $383.15 \mathrm{~K}$ and $1 \mathrm{~atm}$. Intrinsic bond orbital (IBO) calculations were performed in MOLPRO 2015.120 using M06/def2-TZVP. ${ }^{21}$ Density fitting was employed to accelerate calculations in MOLPRO using the def2-TZVP JK-fitting basis set. Molecular and orbital depictions were made using the IBOView program. ${ }^{11,12}$ For NBO calculations, the NBO 5.G ${ }^{13}$ program was used, and the d orbital occupation numbers were generated following the protocol described in ref 22 .

\section{RESULTS AND DISCUSSION}

\subsection{Experimental Studies and Kinetic Analysis}

First, we set out to determine the kinetic robustness of the reaction of 4-octyne with azobenzene catalyzed by $\left[\mathrm{py}_{2} \mathrm{TiCl}_{2} \mathrm{~N}^{t} \mathrm{Bu}\right]_{2}$ by in situ ${ }^{1} \mathrm{H}$ NMR same-excess analysis. ${ }^{23,24}$ The dimeric catalyst $\left[\mathrm{py}_{2} \mathrm{TiCl}_{2} \mathrm{~N}^{\mathrm{B}} \mathrm{Bu}\right]_{2}$ was chosen due to greater solubility over previously reported $\mathrm{py}_{3} \mathrm{TiCl}_{2}(\mathrm{NR})$ species and because formation of $\mathrm{N}^{t} \mathrm{Bu}$ pyrrole products then provides information on the amount of catalyst activation. In experiment $1,0.44 \mathrm{mmol}$ of azobenzene and $2.3 \mathrm{mmol}$ of 4-octyne were reacted with $0.04 \mathrm{mmol}$ of $\left[\mathrm{py}_{2} \mathrm{TiCl}_{2} \mathrm{~N}^{t} \mathrm{Bu}\right]_{2}$. In experiment 2, $0.34 \mathrm{mmol}$ of azobenzene and $1.77 \mathrm{mmol}$ of 4-octyne were reacted with 0.04 mmol of $\left[\mathrm{py}_{2} \mathrm{TiCl}_{2} \mathrm{~N}^{t} \mathrm{Bu}\right]_{2}$. Overlay of these two reactions produces good overlapping kinetic traces indicating no catalyst decomposition and no significant catalyst induction period caused by the $\mathrm{N}^{t} \mathrm{Bu}$ group (Figure 2).

Having established that this catalyst system is well-behaved, we next sought to determine the rate law using variable time normalization analysis (VTNA) of each individual component of the reaction. ${ }^{27,28}$ In VTNA experiments, the time scale is normalized as a time integral (approximated via the trapezoid rule) of one component of the reaction to remove the kinetic effect of that component from the reaction profile. ${ }^{27}$ By systematically varying concentrations of each component, one can rapidly construct graphical overlays that indicate component order. The VTNA overlay plots of each component of the reaction of 3-hexyne with azobenzene catalyzed by $\left[\mathrm{py}_{2} \mathrm{TiCl}_{2} \mathrm{~N}^{t} \mathrm{Bu}\right]_{2}$ (catalyst, 3-hexyne, azobenzene, pyridine) are presented in Figure 3, and the approximate derived rate law is provided in eq 1.

$$
\text { rate }=k \frac{[\mathrm{Ti}]^{0.5}[3 \text {-hexyne }]^{2}}{[\mathrm{PhNNPh}][\text { pyridine }]}
$$

The half-order dependence on [Ti] indicates a monomer-dimer equilibrium and that at this concentration the bulk of catalyst is dimerized. ${ }^{25,26}$ This is consistent with many other Ti- 
catalyzed reactions involving Ti imido intermediates such as alkyne hydroamination, wherein bridged imidos are often off-cycle resting states. ${ }^{29-34}$ Unlike hydroamination reactions, however, the Ti dimer species is on cycle in $[2+2+1]$ catalysis, as azobenzene cleavage requires dimerization (vide infra). The reaction is first-order inhibited by $[\mathrm{PhNNPh}]$, indicating that productive catalyst reoxidation by $\mathrm{PhNNPh}$ is kinetically unimportant, and instead that $\mathrm{PhNNPh}$ can inhibit catalysis through competitive binding with alkyne at one or more points along the catalytic cycle. As a result, the second-order dependence on [3-hexyne] indicates that either second alkyne insertion or reductive elimination is rate-determining. Taken together, this rate law indicates a likely Ti monomer/ dimer equilibrium prior to reversible [2 +2$]$ imido + alkyne cycloaddition followed by irreversible, rate-determining 3-hexyne second insertion or reductive elimination (Figure 4). The specific step(s) at which pyridine and azobenzene inhibits catalysis cannot be experimentally determined since the inhibition could potentially occur at any Ti intermediate prior to the rate-determining step.

Given the initial mechanistic insights above, we next turned to computation to more deeply examine the mechanism. First, we wanted to determine the number and type of $\mathrm{L}$ donor ligands bound to the active species at each step in the catalytic cycle: the rate law indicates an inhibition by pyridine and azobenzene, but it is unclear at what stage this occurs. One could envision pyridine, alkyne, or azobenzene coordinated to the Lewis acidic metal during catalysis. Additionally, we were interested in probing the steps of catalysis that are not kinetically observable (reductive elimination and diazene disproportionation) to determine at a fundamental level how and why this unique $\mathrm{Ti}^{\mathrm{I}} / \mathrm{Ti}^{\mathrm{IV}}$ mechanism takes place.

\subsection{DFT Analysis of the Mechanism and Effects of Ligands}

We first examined the energetics of the catalytic reaction of 2-butyne with azobenzene to determine the rate-determining step in the mechanism and the effects of different ligands on the individual steps. The precatalyst $\mathrm{py}_{3} \mathrm{TiCl}_{2}(\mathrm{NPh})$ can potentially undergo dissociation of pyridines such that 1,2, or no pyridine ligands are bound; furthermore, 2-butyne or azobenzene could also act as a ligand. Therefore, we performed a series of calculations such that we can isolate what ligands are most probably bound to Ti for each intermediate and transition state over the course of the reaction. In general, there is no significant barrier with the addition or removal of a pyridine ligand or alkyne; however, the same cannot be said about the addition of azobenzene, as we discuss later in this section.

Figure 5 shows the free energy profile for the formation of $N$-phenyl tetraethylpyrrole from 2-butyne. Dissociation of one pyridine from $\mathrm{py}_{3} \mathrm{TiCl}_{2}(\mathrm{NPh})(\mathbf{C A T})$ to IM1 is favorable by $8.2 \mathrm{kcal} / \mathrm{mol}$ in $\mathrm{PhCF}_{3}$, while the removal of two pyridines is roughly thermoneutral. However, liberation of all three pyridines to generate a naked 3-coordinate complex, binding of 2-butyne, and binding of azobenzene are all shown to be unfavorable. Therefore, at the start of the catalytic cycle Ti is likely to be coordinated to one or two pyridines. This is consistent with ${ }^{1} \mathrm{H}$ NMR spectroscopic evidence that shows that the pyridine trans to the imido is already in coordination equilibrium at room temperature; thus, at elevated temperature, more complex pyridine coordination equilibria are likely involved. 
After pyridine loss, 2-butyne can then coordinate to Ti to make IM2, which is an endergonic process for all possible ligand combinations. As the catalyst coordinates to the $\pi$-bond of the alkyne, the lowest energy IM2 structure contains only one pyridine to minimize steric effects. This species then reacts through $[2+2]$ cycloaddition to the imido $\mathrm{Ti}=\mathrm{N}$ bond through TS1, with a barrier of $13.6 \mathrm{kcal} / \mathrm{mol}$ (assuming one bound pyridine) to form azatitanacyclobutene (IM3). The relative free energy differences between zero, one, or two pyridines bound to IM3 are relatively small, suggesting that all of these complexes may play a role during the cycloaddition step. Likewise, coordination of the second equivalent of 2butyne to IM4 can readily occur with either zero or one pyridine.

The 2-butyne insertion transition state TS2 proves to be the rate-determining step. Unlike previous steps where several ligand combinations were energetically feasible, this step has significant free energy differences between the different ligand combinations, strongly suggesting that the catalyst has a single pyridine ligand during TS2. The reaction barrier is $5.3 \mathrm{kcal} / \mathrm{mol}$ compared to $\mathbf{I M 4}, 29.6 \mathrm{kcal} / \mathrm{mol}$ compared to the starting catalyst while being exergonic to form azatitanacyclohexadiene IM5 by $33.6 \mathrm{kcal} / \mathrm{mol}$. This also accounts for the observed inhibition by azobenzene and pyridine, since coordination of either of these species significantly raises the energy of all species through TS2.

Next, C-N reductive elimination from IM5 occurs to form a Ti ${ }^{\mathrm{II}}$-bound pyrrole IM6. Remarkably, despite forming a formally $\mathrm{Ti}^{\mathrm{II}}$ species, the formation of IM6 has a relatively small barrier of $10.6 \mathrm{kcal} / \mathrm{mol}$ for the single pyridine bound catalyst and is exergonic. We discuss this step in detail in section 3.3 to show how it is likely that a true $\mathrm{Ti}^{\mathrm{II}}$ intermediate is formed at this stage of the catalytic cycle.

The next step is release of the pyrrole product to form IM7. Surprisingly, we find that even with a single pyridine ligand the energy required to dissociate the pyrrole is only $18.9 \mathrm{kcal} /$ mol, significantly lower than the rate-determining step. This suggests that the formation of $\mathrm{Ti}^{\mathrm{II}}$ is readily accessible.

Since IM6 with bound azobenzene is significantly lower in energy than all other ligands, we examined this step in greater detail. It is clear from Figure 5 that azobenzene being bound to Ti prior to IM6 is significantly unfavorable for productive catalysis, consistent with the kinetic inhibition observed experimentally. Therefore, to proceed over TS3 to form IM6 the catalyst must have either 0 or 1 bound pyridine ligands. However, after the reductive elimination, an azobenzene could bind to IM6 to aid in pyrrole release via associative displacement as suggested by Wang. ${ }^{10}$ Therefore, we calculated the barrier for associative displacement of pyrrole by azobenzene, shown in Figure 6 as TS4.

Figure 6 compares direct pyrrole release to form $\mathrm{Ti}^{\mathrm{II}}$ with azobenzene coordination to dissociate pyrrole, which would ostensibly avoid a discrete formally $\mathrm{Ti}^{\mathrm{II}}$ intermediate through direct electron transfer from pyrrole to azobenzene. Our calculations suggest that the pathway requiring azobenzene binding has a transition-state barrier of $23.1 \mathrm{kcal} / \mathrm{mol}$ compared to only $18.9 \mathrm{kcal} / \mathrm{mol}$ for direct pyrrole dissociation. These results are in direct contrast to previous calculations from the Wang group, who proposed a "redox neutral" associative interchange mechanism that was predicated on azobenzene coordination prior to 
pyrrole release to avoid discrete, free $\mathrm{Ti}^{\mathrm{II}}$ intermediates. ${ }^{10}$ We believe the inclusion of solvent polarization effects within our geometry optimizations leads to the differences in conclusions: other groups have optimized Ti catalysts in implicit solvation and have found good agreement with experimental kinetics. ${ }^{35}$ Additionally, we have found experimentally that stoichiometric pyrrole production (and subsequent catalytic alkyne cyclotrimerization by $\mathrm{Ti}^{\mathrm{II}}$ ) is possible in the absence of azobenzene. ${ }^{36}$ Taken together, this suggests that azobenzene binding for pyrrole release is not a requirement for $[2+2+1]$ pyrrole synthesis and that free $\mathrm{Ti}^{\mathrm{II}}$ intermediates are plausible under catalytic conditions.

Finally, IM7 is reoxidized by binding azobenzene to form IM8. IM8 is best described as a $\mathrm{Ti}^{\mathrm{IV}}$ hydrazido ${ }^{2-}$ species wherein the electron pair from the $\mathrm{Ti}^{\mathrm{II}}$ has been fully backdonated into the N-N $\pi^{*}$ of azobenzene (vide infra), as shown in Figure S114c. Overall, the catalytic production of $N$-phenyltetraethylpyrrole is exergonic by $55.1 \mathrm{kcal} / \mathrm{mol}$ with a barrier of 29.6 $\mathrm{kcal} / \mathrm{mol}$ if the most energetically favorable ligands are used, which is a reasonable barrier for the $110{ }^{\circ} \mathrm{C}$ temperature.

To further validate the computationally derived energy values, we carried out Arrhenius analysis on the reaction of 4-octyne with azobenzene catalyzed by $\left[\mathrm{py}_{2} \mathrm{TiCl}_{2} \mathrm{~N}^{t} \mathrm{Bu}\right]_{2}$. Figure 7 shows the Arrhenius-like plot for 4-octyne giving an activation enthalpy of $16.3 \pm 0.6 \mathrm{kcal} /$ mol. Computationally, the activation enthalpy from CAT to TS2 for 4-octyne is $21.1 \mathrm{kcal} /$ mol; therefore, this represents relative good agreement between our DFT model and the experimental result.

The overall rate constant in an Eyring equation ${ }^{37}$ type form is

$$
k=\kappa\left(\frac{k_{\mathrm{B}} T}{h}\right) e^{\Delta S * / k_{\mathrm{B}}} e^{\Delta H * / k_{\mathrm{B}} T}
$$

where $\Delta H^{*}$ and $\Delta S^{*}$ are the change in enthalpy and entropy from CAT to TS2, $x$ is the transmission coefficient, $h$ is Planck's constant, and $k_{\mathrm{B}}$ is Boltzmann's constant. By using the experimentally measured rates and our DFT calculations for the enthalpy $(21.1 \mathrm{kcal} / \mathrm{mol})$ and entropy $(18.8 \mathrm{cal} /(\mathrm{mol} \mathrm{K}))$, we can then extract that $\kappa$ is 0.017 . The small transmission coefficient shows that this reaction occurs in the high-friction regime of Kramer theory, ${ }^{38}$ showing that solvent viscosity likely plays a role in the kinetics. There is a large geometry change that occurs from TS2 to IM5, yet a small geometry change between IM4 and TS2; therefore, there is a relatively large solvent reorganization required after the transition state to proceed to products, which leads to a small transmission coefficient.

\subsection{Mechanism and NBO/IBO Analysis of $\mathrm{C}-\mathrm{N}$ Reductive Elimination}

Our calculations show that dissociation of pyrrole from $\mathrm{Ti}^{\mathrm{II}}$ intermediates is more favorable than azobenzene binding to the $\mathrm{Ti}^{\mathrm{II}}$-pyrrole complex. But the question remains if formal reduction occurs during $\mathrm{C}-\mathrm{N}$ bond formation or if the pyrrole acts as a fully redox active ligand through bilateral donation and back-donation, obviating the need for charge distribution onto Ti. Therefore, we calculated the NBOs and performed IBO analysis to gain insight into this step. 
In complicated binding situations involving noninnocent ligands and covalent metal-ligand bonding, formal oxidation-state assignment from first-principles or DFT calculations can become ambiguous or arbitrary - after all, oxidation state is merely a formalism used to describe extreme ends of a spectrum of bonding. However, it is often useful to describe systems in terms of relative oxidation/reduction. D' Acchioli et al. suggested using the dorbital occupations ${ }^{22}$ based on NBO theory instead of atomic charge to infer to the natural oxidation state of a transition metal, ${ }^{39}$ since simple changes to the primary covalent coordination sphere (i.e., changing from alkoxide to amide) can dramatically impact the computed charge on the metal. Therefore, we use both NBOs and IBOs to argue that $\mathrm{C}-\mathrm{N}$ bond formation from IM5 to IM6 occurs through a formal +4/+2 reductive elimination.

The results of $3 \mathrm{dz}^{2} \mathrm{NBO}$ orbital occupation calculations for all pyrrole-forming steps of the catalytic cycle (assuming one bound pyridine) are listed in Table 1, with the full list of all $d$ orbitals in Table S8. All of the d orbital occupations remain mostly constant throughout the reaction except for the $3 \mathrm{dz}^{2}$ orbital occupation. By analyzing the $3 \mathrm{dz}^{2}$ orbital and relating the occupation of this orbital to the formal oxidation state for compounds with known oxidation states, we can infer the oxidation state for all intermediates. As a benchmark for $\mathrm{Ti}^{\mathrm{II}}$ complexes, the $3 \mathrm{dz}^{2}$ values for $\mathrm{TiCl}_{2},\left[\mathrm{TiCl}_{4}\right]^{2-}, \mathrm{TiCl}_{2} \mathrm{py}_{2}$, and $\mathrm{TiCl}_{2} \mathrm{py}_{4}$ were found to range between 0.65 and 0.82. As a benchmark for $\mathrm{Ti}^{\mathrm{IV}}$ complexes, IM1-IM5 and $\mathrm{TiCl}_{4}$ were calculated to have $3 \mathrm{dz}^{2}$ values between 0.29 to 0.44 . Therefore, intermediates with $3 \mathrm{dz}^{2}$ values closer to 0.4 can be assigned a formal +4 oxidation state and closer to $0.6 \mathrm{a}+2$ oxidation state.

From this analysis, we assign IM5 a formal +4 oxidation state $\left(3 \mathrm{dz}^{2}=0.44\right)$ and IM6 a formal +2 oxidation state $\left(3 \mathrm{dz}^{2}=0.61\right)$. However, the $3 \mathrm{dz}^{2}$ occupation of 0.61 is on the lower end of occupation for $\mathrm{Ti}^{\mathrm{II}}$, which does suggest strong bilateral donation and backdonation into the pyrrole $\pi^{*}$. This backdonation can be seen in the calculated bond lengths of the pyrrole in IM6, where $\mathrm{C} 1-\mathrm{N}, \mathrm{C} 4-\mathrm{N}$, and $\mathrm{C} 4-\mathrm{C} 3$ are elongated (Figure 8). Similarly, the $3 \mathrm{dz}^{2}$ value (0.64) for $\mathrm{TiCl}_{2} \mathrm{py}_{4}$, which can also backdonate into the ligand framework, is

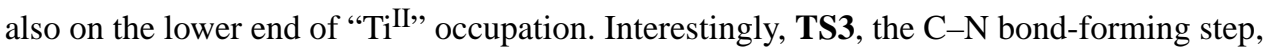
has a $3 \mathrm{dz}^{2}$ of 0.54 , suggesting that the two-electron reduction is happening through this transition state. IM7 is assigned a +2 oxidation state before the catalysts binds with azobenzene, after which it returns to the +4 oxidation state in IM8.

Further evidence for the reductive elimination mechanism is obtained through IBO analysis. By obtaining IBOs along the reaction coordinate, the continuous rearrangement of IBOs can be correlated to electron flows and bond rearrangements and then expressed by the curved arrow formalism. ${ }^{11,12}$ By construction, a minimal number of IBOs change their nature during a reaction to make it clear and straightforward to analyze the mechanism and identify electron flow.

Figure 6 shows the IBOs for the reductive elimination step from IM5 to IM6. Figure 6a shows that the lone pair on the $\mathrm{N}$ atom in IM5 (blue orbital) rotates and attacks $\mathrm{C} 4$ to form the new $\mathrm{C}-\mathrm{N} \sigma$ bond in an electrocyclic fashion, similar to how a $\mathrm{C}-\mathrm{C}$ bond is formed in a Nazarov cyclization of divinylketones. ${ }^{40}$ Simultaneously, the orange orbital ( $\pi$ bond on $\mathrm{C} 1$ and $\mathrm{C} 2$ ) and the magenta orbital ( $\pi$ bond on $\mathrm{C} 3$ and $\mathrm{C} 4$ ) simply shift during the reductive 
elimination and become localized on $\mathrm{C} 1, \mathrm{C} 2$, and $\mathrm{C} 3$. Concurrent with electrocyclization, Figure $6 \mathrm{~b}$ shows the fate of the Ti-C and Ti-N $\sigma$-bonding orbitals. As the electrocyclization takes place, these two orbitals rotate perpendicular to the forming pyrrole ring, becoming the basis for a $\pi$ backbonding interaction with Ti. The net result of this electron movement (Figure 6c) is to generate a bound pyrrole whose binding can be described as an $\eta^{3}$-allyl interaction between $\mathrm{C} 1, \mathrm{C} 2, \mathrm{C} 3$, and $\mathrm{Ti}$ and a strong $\pi$ backbonding interaction between $\mathrm{T}$, $\mathrm{N}$, and $\mathrm{C} 4$. This bonding picture is consistent with the calculated bond lengths in IM6, where $\mathrm{C} 1-\mathrm{C} 2$ and $\mathrm{C} 2-\mathrm{C} 3$ are average $(\sim 1.4 \AA)$, while $\mathrm{C} 3-\mathrm{C} 4, \mathrm{C} 4-\mathrm{N}$, and $\mathrm{N}-\mathrm{C} 1$ are elongated $(\sim 1.45 \AA)$ compared to normal pyrrole bond lengths.

This electrocyclic reductive elimination is unique and provides an important piece of data on $\mathrm{C}-\mathrm{X}(\mathrm{X} \neq \mathrm{H})$ reductive eliminations on Ti: direct $\mathrm{M}-\mathrm{C} \sigma$ reductive coupling on Ti is virtually unknown; it appears as though in almost all cases Ti organometallics would energetically prefer $\mathrm{H}$ abstraction, ${ }^{41,42}$ radical decomposition, ${ }^{43}$ substitution, 44 or electrocyclization to classical two-electron reductive elimination pathways seen with late transition metals. In fact, in our previous report on Ti-catalyzed alkyne/alkene/nitrene coupling, direct $\mathrm{C}-\mathrm{N}$ bond forming was never observed. ${ }^{45}$ Since these systems had semisaturated ring systems, they are unable to undergo electrocyclization and instead access alternative reductive pathways. Similarly, the Ti-catalyzed Pauson-Khand reaction, an example of apparent $\mathrm{C}-\mathrm{C}$ direct reductive coupling, may instead proceed through a related $\pi$-electrocyclization-type pathway. ${ }^{46,47}$

\subsection{Solvent Effects on the Mechanism and Rate}

Next, the effect of solvents on the rate of catalysis was examined by varying the solvent dielectric from $2.03\left(\mathrm{C}_{6} \mathrm{D}_{12}\right)$ to $10.5\left(\mathrm{C}_{2} \mathrm{H}_{4} \mathrm{Cl}_{2}\right)$, and the data are summarized in Figure 9. There is a strong correlation between rate and dielectric constant, with high dielectric solvents $\left(\mathrm{C}_{2} \mathrm{H}_{4} \mathrm{Cl}_{2}, \mathrm{C}_{6} \mathrm{D}_{5} \mathrm{Br}, \mathrm{PhCF}_{3}\right)$ yielding fast, productive catalysis and low dielectric solvents (cyclohexane, $\mathrm{C}_{6} \mathrm{D}_{6}, \mathrm{C}_{6} \mathrm{~F}_{6}$ ) performing poorly. Additionally, there is no obvious arene coordination or other solvent coordination effect to the rate since $\mathrm{C}_{2} \mathrm{H}_{4} \mathrm{Cl}_{2}, \mathrm{C}_{6} \mathrm{D}_{5} \mathrm{Br}$, and $\mathrm{PhCF}_{3}$ all have similar rates.

Curiously, the data show that $\mathrm{PhCF}_{3}, \mathrm{C}_{2} \mathrm{H}_{4} \mathrm{Cl}_{2}$, and $\mathrm{C}_{6} \mathrm{D}_{5} \mathrm{Br}$ all have very similar rates, despite the fact that $\mathrm{C}_{6} \mathrm{D}_{5} \mathrm{Br}$ 's dielectric constant is only 5.4, while $\mathrm{PhCF}_{3}$ and $\mathrm{C}_{2} \mathrm{H}_{4} \mathrm{Cl}_{2}$ are 9.18 and 10.5, respectively. This step function behavior in the rate suggests a deeper mechanistic feature in the role of the solvent; therefore, we performed calculations on a subset of these solvents to probe the effect of dielectric constant on the rate.

Figure 10 shows the calculated catalytic cycle for three of the experimentally used solvents, $\mathrm{PhCF}_{3}, \mathrm{C}_{6} \mathrm{D}_{5} \mathrm{Br}$, and $\mathrm{C}_{6} \mathrm{~F}_{6}$. Overall, the catalytic picture looks largely the same, with TS2 being the highest overall energy of the catalytic cycle. However, contrary to experimental expectations, the free energy difference between CAT and TS2 actually increases with increasing dielectric constant with barriers of 29.6, 29.1, and $25.5 \mathrm{kcal} / \mathrm{mol}$ barriers for $\mathrm{PhCF}_{3}, \mathrm{C}_{6} \mathrm{D}_{5} \mathrm{Br}$, and $\mathrm{C}_{6} \mathrm{~F}_{6}$, respectively. Since the TS2 barrier controls the rate, these data suggest that the increase in the barrier with high dielectric constant is contrary to experiment. Given that we are using an implicit solvation model, the associated errors with such a model can certainly lead to $3-5 \mathrm{kcal} / \mathrm{mol}$ errors. ${ }^{48}$ Furthermore, as discussed in the 
Supporting Information, we only changed the dielectric constant of the solvent and ignored other changes in the solvent such as the thermal expansion coefficient or the surface tension at interface. Additionally, we showed that this reaction takes place in the high friction regime of Kramer rate theory; therefore, the solvent viscosity, which was not taken into effect here, plays a role in the kinetics. Therefore, the discrepancy between our calculations and experiments could be from not including these effects.

Despite this, an interesting trend can be seen which might suggest why experimentally the reaction rate increases with dielectric constant. The free energy difference between IM6 and IM7 is increasing with decreasing dielectric constant, going from $18.9\left(\mathrm{PhCF}_{3}\right)$ to 21.9 $\left(\mathrm{C}_{6} \mathrm{D}_{5} \mathrm{Br}\right)$ to $25.8 \mathrm{kcal} / \mathrm{mol}$ for $\mathrm{C}_{6} \mathrm{~F}_{6}$. These data show that high dielectric constant solvents are able to more adequately stabilize free $\mathrm{Ti}^{\mathrm{II}}$ species. Therefore, it could be that in $\mathrm{C}_{6} \mathrm{~F}_{6}$ slower ligand dissociation rates at various steps of catalysis may play a role in kinetically relevant equilibria or related processes.

Additionally, it is important to note how sensitive these calculations are to fully relaxing the geometries in the associated solvent. We also performed single-point energy calculations in these three solvents using $\mathrm{PhCF}_{3}$ solvent-optimized geometries (Figure S111). Using this simplified protocol, there is a dramatically higher energy difference between IM6 and IM7, which would lead to the inaccurate conclusion that the free energy difference between IM6 and $\mathbf{I M 7}$ was becoming the rate-determining step for $\mathrm{C}_{6} \mathrm{~F}_{6}$. This further demonstrates the large role solvent plays in the dissociation of pyrrole. Additionally, the differences between Figure 10 and Figure S111 emphasize the need for careful computations in the description of solvent effects.

\subsection{Mechanism for Regeneration of the Catalyst via Disproportionation}

Next, we computed the regeneration of the active Ti imido (CAT') from the $\eta^{2}$-hydrazido adduct IM8. Previously, we hypothesized that this reaction proceed through a dimerization process to make a bridged $\mathrm{Ti}_{2} \mathrm{~N}_{4} 6$-membered metallacycle that would then eject azobenzene and regenerate $2 \mathrm{Ti}$ imidos in a retro-[2+2+2] reaction. However, we were unable to experimentally interrogate this mechanism because simple ligand loss from model complexes was rate-limiting.

The computed mechanism for regeneration of the Ti imido catalyst is shown in Figure 11. We were unable to locate a reaction pathway that proceeded through the originally proposed retro-[2+2+2]. ${ }^{6}$ Here, we start with two IM8 complexes with one pyridine on each complex since pyrrole release likely occurs with one pyridine (vide supra). For convenience, we reset the energy scale to zero here, but IM8 is actually $-53.4 \mathrm{kcal} / \mathrm{mol}$ relative to the starting catalyst; therefore, we do not expect, nor is experimentally observed, that any step in the regeneration pathway to be rate determining. Two equivalents of IM8 first dimerize through one chlorine atom and one azobenzene to form IM9. Next, IM9 then reacts to break the bridging azobenzene $\mathrm{N}-\mathrm{N}$ bonds through TS5, forming an unsymmetric bis imidobridged four-membered ring IM10 where the nonreacted azobenzene remains coordinated to one Ti. This dimerization pathway is consistent with previous crossover studies which indicated no azobenzene $\mathrm{N}-\mathrm{N}$ scrambling during catalysis. ${ }^{6}$ Subsequently, there is a reaction 
barrier of $9.6 \mathrm{kcal} / \mathrm{mol}$ to liberate this azobenzene to generate IM11, a bridging imido dimer. These species are often the resting states in other $\mathrm{Ti}$ imido-catalyzed reactions such as hydroamination, ${ }^{29-34}$ and in fact, this species is close in energy to $\mathbf{C A T}^{\prime}$.

There are multiple energetically accessible pathways from IM11 to CAT', we show the lower energy pathway here and a secondary pathway in the Supporting Information (Figure S112), which uses different regoisomers. The pathway shown here involves first gearing the imido-bridge dimer IM11 to a chloro-bridged dimer IM13 (the experimental crystal structures of $\left[\mathrm{TiCl}_{2}\left(\mathrm{NC}_{6} \mathrm{H}_{4} \mathrm{Me}\right) \mathrm{py}_{2}\right]_{2}$ and $\left[\mathrm{TiCl}_{2}\left(\mathrm{NC}_{6} \mathrm{~F}_{5}\right) \mathrm{py}_{2}\right]_{2}$ are chloro-bridged $\left.{ }^{29 \mathrm{~b}}\right)$ in contrast to direct splitting of IM11 as proposed by the Wang group. ${ }^{10}$ In this chloro-bridged splitting pathway, IM11 first isomerizes by overcoming a $17.4 \mathrm{kcal} / \mathrm{mol}$ barrier in TS7 to move from a bis imido-bridge to a mixed imido/chloro-bridge IM12. Next, the second isomerization takes place, this time only requiring $9.5 \mathrm{kcal} / \mathrm{mol}$ of energy through TS8 to form bis chloro-bridged IM13. At this point, barrierless addition of pyridines forms a coordinatively saturated IM14, which is exergonic by $9.9 \mathrm{kcal} / \mathrm{mol}$. Finally, the dimer IM14 breaks through a small $3.3 \mathrm{kcal} / \mathrm{mol}$ barrier to regenerate 2 equiv of CAT'.

Regardless of how the dimer dissociates, the free energy difference between IM11 and CAT' is relatively small, suggesting an equilibrium of the dimer and monomer under catalytic conditions. This matches the experimentally observed rate order of [Ti $]^{0.5}$.

\subsection{Alkyne Effects on Reaction Kinetics and Regioselectivity}

Next, the effect of alkyne substitution on the reaction kinetics and product regioselectivity was explored. First, we experimentally examined the rates of 3-hexyne vs 4-octyne (Table 2) to explore any steric differences on reaction rate and compared these to the computationally derived relative rates of 2-butyne, 3-hexyne, and 4-octyne. 2-butyne was not tested experimentally because its low boiling point precludes precise concentration measurements at the elevated reaction temperature. It was found that there was a small observable experimental rate difference between 3-hexyne and 4-octyne. Although Et and ${ }^{n}$ Pr groups have similar $A$ values, their ligand repulsion energies $\left(E_{\mathrm{r}}\right)$ and steric values $\left(E_{\mathrm{S}}\right)$ are quite different, which appears to have some small influence on rate-determining second insertion (TS2). ${ }^{49}$ Consistent with this observation, there is only a small computed energy difference between TS2 for the 3 internal alkyne substrates. The experimental $k_{\text {obs }}$ difference between 3 -hexyne and 4-octyne correlates to a free energy difference of $1.4 \mathrm{kcal} / \mathrm{mol}$, which is in excellent agreement with the computational result of $1.4 \mathrm{kcal} / \mathrm{mol}$. Further computational analysis of the complete catalytic cycle also indicates only small changes in energies between 2-butyne, 3-hexyne, and 4-octyne for other intermediates and transition states (Figure S113).

Unsymmetrical alkynes introduce a new layer of complexity: there are three possible regioisomeric products that result from 2 azatitanacyclobutene intermediates (IM3) and 4 azatitanacy-clohexadiene intermediates (IM5). The selectivites for several unsymmetrical alkynes are shown in Table $3 .{ }^{6}$ Given these results, we were interested in determining the exact pathways through which products were formed, since the 2,4-substituted head-to-tail coupled product $\mathbf{H}$ could be formed through multiple routes (see Figure 13, vide infra). On 
the basis of our initial computational and kinetic results, formation of IM3 is in most cases reversible, while IM5 is irreversible. Thus, in order to understand the origin of selectivity, the equilibrium constants and each individual second insertion rate must be known. As such, we embarked on full kinetic and computational analysis of the selectivity manifold of several unsymmetrical alkynes.

For the purpose of experimentally examining the kinetics of unsymmetrical reactions, phenylpropyne (PhCCMe) derivatives were selected. PhCCMe was determined as the best candidate for kinetic analysis because terminal alkynes are typically plagued by alkyne trimerization side reactions. ${ }^{6}$ Again, we turned to VTNA to determine the rate equation of the reaction of PhCCMe with azobenzene and $\left[\mathrm{py}_{2} \mathrm{TiCl}_{2} \mathrm{~N}^{t} \mathrm{Bu}\right]_{2}$. The VTNA reactions (Figure 12) give a rate equation consistent with the computational analysis (eq 2). In this case, $[\mathrm{PhCCMe}]$ is still second order at low concentrations, and both $[\mathrm{PhNNPh}]$ and [pyridine] were still found to give first order inhibition of the reaction. [Ti] is still 0.5 order, indicating that a change in the alkyne substrate has, unsurprisingly, little effect on the catalyst monomer-dimer equilibrium. However, at high [ $\mathrm{PhCCMe}]$ the order changes to $[\mathrm{PhCCMe}]^{1.5}$ (Figure S40). This change in the rate order indicates that at high concentration of PhCCMe there is population of [2 + 2] cycloadduct IM3 in equilibrium with IM1. Consequently, this perturbs the rate law from rigorous second order. This is in contrast to 3hexyne, which under all tested conditions is second order.

$$
\text { rate }=k \frac{[\mathrm{Ti}][\mathrm{PhCCMe}]^{1.5-2}}{[\mathrm{PhNNPh}][\text { pyridine }]}
$$

Next, the catalytic cycle from precatalyst through IM5 (immediately after irreversible, ratedetermining second alkyne insertion) was calculated for three unsymmetric terminal alkynes, ${ }^{n} \mathrm{BuCCH},{ }^{t} \mathrm{BuCCH}$, and $\mathrm{PhCCH}$. The energies of all selectivity-relevant species are presented in the selectivity manifold in Figure 13. Full computational details and selectivity determination for these three alkynes are available in the Table S9.

For ${ }^{n} \mathrm{BuCCH}$, there is very little preference for forming either [2+2] regioisomer $\mathbf{I M}_{\mathrm{A}}$ (electronically favored) or $\mathbf{I M} \mathbf{3}_{\mathrm{B}}$, (sterically favored). Despite the fact that it may seem counterintuitive that Ti would be the sterically "small" fragment of the Ti $=\mathrm{NPh}$ unit, the 2 $\mathrm{Cl}$ ligands provide little spatial hindrance to [2+2] cycloaddition in TS1 in comparison to the $\mathrm{Ph}$ on the imido. In the alkyne insertion step, TS2, going from IM3 to IM5, there is a small $\left(\Delta \Delta G^{\dagger}=1.4 \mathrm{kcal} / \mathrm{mol}\right)$ preference for 1,2 insertion from $\mathbf{I M} \mathbf{3}_{\mathrm{A}}\left(\mathbf{T S} \mathbf{2}_{\mathrm{AD}}\right.$, going to $\left.\mathbf{I M 5} 5_{\mathrm{D}}\right)$, and little preference $\left(\Delta \Delta G^{\ddagger}=0.1 \mathrm{kcal} / \mathrm{mol}\right)$ for either $1,2-\left(\mathbf{T S} 2_{\mathrm{BF}}\right)$ or $2,1-\left(\mathbf{T S} \mathbf{2}_{\mathrm{BE}}\right)$ insertion from $\mathbf{I M} 3_{\mathrm{B}}$. As a result, all possible pathways are kinetically accessible, leading to a distribution of $\mathbf{G}, \mathbf{H}$, and $\mathbf{I}$ that agrees well with experimental data. Product $\mathbf{H}$ is the major product because the lowest energy pathway $\left(\mathbf{I M} \mathbf{3}_{\mathrm{A}}\right.$ to $\left.\mathbf{I M} \mathbf{5}_{\mathrm{D}}\right)$ and the second lowest energy pathway $\left(\mathbf{I M} \mathbf{3}_{\mathrm{B}}\right.$ to $\left.\mathbf{I M 5 _ { \mathrm { E } }}\right)$ both lead to $\mathbf{H}$.

${ }^{t} \mathrm{BuCCH}$ regioselectivity is dominated by sterics. Both [2 +2$]$ cycloaddition pathways are energetically accessible $>100{ }^{\circ} \mathrm{C}$, but there is a huge kinetic preference $\left(\Delta \Delta G^{\dagger}=7.2 \mathrm{kcal} /\right.$ 
mol) as well as a thermodynamic preference $\Delta G=4.5 \mathrm{kcal} / \mathrm{mol}$ ) for formation of the sterically favored $\mathbf{I M} \mathbf{3}_{\mathrm{B}}$ due to the increased size of ${ }^{t} \mathrm{Bu}$ vs ${ }^{n} \mathrm{Bu} .{ }^{50} \mathrm{In}$ the second insertion step from favored $\mathbf{I M} \mathbf{3}_{\mathrm{B}}$, there is a large steric preference for 2,1-insertion over 1,2-insertion $\left(\Delta \Delta G^{\dagger}=6.1 \mathrm{kcal} / \mathrm{mol}\right.$ for $\mathbf{T S} \mathbf{2}_{\mathrm{BE}}$ over $\left.\mathbf{T S} \mathbf{2}_{\mathrm{BF}}\right)$, and as a result, ${ }^{t} \mathrm{BuCCH}$ produces solely $\mathbf{H}$.

Finally, $\mathrm{PhCCH}$ again has a slight kinetic and thermodynamic preference for the formation of the sterically preferred $\mathbf{I M} \mathbf{3}_{\mathrm{B}}$ over $\mathbf{I M} \mathbf{3}_{\mathrm{A}}$. Additionally, there is a low-energy pathway for sterically preferred 2,1-insertion in the second step (TS2 $\mathbf{B E}_{\mathrm{E}}$ ) leading to $\mathbf{I M 5 _ { \mathrm { E } }}$ and ultimately onto $\mathbf{H}$, which is the experimentally determined major product. However, the computational selectivity significantly favors formation of $\mathbf{I}$. This is because $\mathbf{T S} \mathbf{2}_{\mathrm{BF}}$ converges to a lowestenergy state that has an arene $\pi$-stacking interaction. Since our simplistic rate theory does not take ensemble averages into account, the contribution of other, nonstacked close-inenergy states to the ensemble partition function at high temperature is missed, disproportionally increasing the rate of forming $\mathbf{I M} \mathbf{5}_{\mathrm{F}}$ that yields product $\mathbf{I}$. Nonetheless, excluding this pathway the computational pathways and selectivities for all three alkynes match experimental data well.

Next, we computationally investigated the regioselectivity of reactions with $\mathrm{PhCCMe}$ (Figure 14). Unlike in the terminal alkynes, [2 +2] cycloaddition is most influenced by electronic effects of the alkyne substituents: electronically favored $\mathbf{I M} \mathbf{3}_{\mathrm{L}}$ is both kinetically and thermodynamically favored over $\mathbf{I M} \mathbf{3}_{\mathrm{K}}$, and as a result, product $\mathbf{Q}$ is made in lowest quantity since it can only originate from $\mathbf{I M} \mathbf{3}_{\mathrm{K}}$. Interestingly, much like with ${ }^{n} \mathrm{BuCCH}$, there is again little kinetic preference for the regioselectivity of second insertion, leading to significant quantities of both $\mathbf{R}$ and $\mathbf{S}$.

In summary, the regioselectivity of pyrrole formation in terminal alkynes is driven primarily by sterics, where the degree of selectivity is dependent on the size and nature of the alkyne functional group. In contrast, for an internal alkyne such as phenylpropyne where the steric bias is not as obvious, inductive effects have a larger impact on product distribution. ${ }^{51}$ Ironically, the head-to-tail coupled product $(\mathbf{H}$ or $\mathbf{R})$ is the major product no matter whether sterics or electronics is the controlling selectivity factor. This unfortunate phenomenon is a function of the bifurcating selectivity manifold, wherein two different pathways can later merge to give a common product.

\subsection{Phenylpropyne Substitution Effects and Hammett Analysis}

Given the computational result of the importance of inductive effects in PhCCMe regioselectivity, we next carried out Hammett analysis using various para-substituted phenylpropyne derivatives to determine the transition-state electronic effects on the rate of reactivity and regioselectivity. A survey of five different phenylpropynes indicates a very strong linear correlation between rate and electron donicity (Figure 15). This correlation most likely stems from the increased Lewis basicity of the alkyne, which leads to an increased rate of coordination to Ti, which should assist in both [2+2] cycloaddition and 1,2-alkyne insertion. ${ }^{52}$

Analysis of the regioselectivity in electronically different phenylpropynes reveals an interesting trend in regioselectivity: decreasing electron density on the alkyne decreases the 
formation of 3,4-dimethyl-1,2,5-triphenylpyrrole $\mathbf{Q}$ relative to the other two regioisomers (Figure 15, bottom). We propose that this result indicates that there is a bias against formation of the electronically disfavored azatitanacyclobutene intermediate $\mathbf{K}$. This is consistent with a picture in which electron-withdrawing groups on the phenyl ring stabilize partial negative charge buildup on the carbon adjacent to the phenyl ring in $\mathbf{T S} \mathbf{1}_{\mathrm{L}}$ and likewise destabilize positive charge buildup on carbon in $\mathbf{T S 1}_{\mathrm{K}}$ (Figure 16). It is difficult to interpret the effects this may have on the insertion or reductive elimination steps since the electronic effect now influences the partial charges on both the reactive intermediate $\left(\mathbf{I M} \mathbf{3}_{\mathrm{K}}\right.$ or $\mathbf{I M} 3_{\mathrm{L}}$ ) as well as the alkyne.

\subsection{Catalyst Effects on Reaction Kinetics and Regioselectivity}

Next, we investigated simple anionic ligand changes on the catalyst using $\mathrm{Cl}, \mathrm{Br}$, and I to probe electronic and steric effects based on ligand donor parameters (LDP) previously generated for early transition metals. ${ }^{53,54}$ These values allow direct comparison between different ligand sets based on their donor ability (LDP) and steric contributions (\% vol) to the metal center. A general periodic trend can be seen (Table 4): the larger, poorer donor ligand $\mathrm{I}$ is significantly faster than the smaller, stronger donor ligand $\mathrm{Cl}$. Interestingly, the rate effect of changing the $\mathrm{X}$ ligand is significantly smaller than simply using a bis(pyridine) catalyst $\left[\mathrm{py}_{2} \mathrm{Cl}_{2} \mathrm{TiN}^{t} \mathrm{Bu}\right]_{2}$ instead of $\mathrm{py}_{3} \mathrm{TiCl}_{2} \mathrm{~N}^{t} \mathrm{Bu}$. Since the data include only three points, we chose not to overinterpret the data and assign a fitted model to determine the relative contribution of LDP vs \% BurV. ${ }^{55}$

Further analysis of these catalyst effects on phenylpropyne pyrrole regioselectivity yields an increase in the selectivity for 2,5-dimethyl-1,3,4-triphenylpyrrole $\mathbf{S}$ and decreasing selectivity for $\mathbf{Q}$ when moving from $\mathrm{Cl}$ to I (Table 5). We propose a compounding electronic and steric effect on the reaction mechanism to achieve this selectivity. We hypothesize that the initial $[2+2]$ is primarily governed by increased electrophilicity of the titanium center/ polarization of the Ti imido favoring $\mathbf{T S} \mathbf{1}_{\mathrm{L}}$ and $\mathbf{I M} \mathbf{M}_{\mathrm{L}}$. This is in agreement with the Hammett results with substituted arylpropynes. Steric effects then contribute for the insertion step, where the larger iodide ligands disfavor putting the sterically encumbered aryl group $a$ to Ti relative to the smaller chloride ligands.

\subsection{Azobenzene Effects on Reaction Kinetics}

Because of the inverse order in [azobenzene], we hypothesized that altering the electronics or sterics of the diazene could potentially lead to a change in rate. Seven para-substituted aryldiazenes were tested to generate the Hammett plot shown in Figure 17 (top). A linear correlation was found between strong EDG (OMe) to weakly EWG $(\mathrm{F})$, giving a general decrease in reaction rate. We hypothesize this decrease in rate is due to decreased Lewis acidity of the metal center containing a more electron-rich imido ligand, which should inhibit alkyne binding. Interestingly, strongly EWG groups $\left(\mathrm{Cl}, \mathrm{OCF}_{3}\right)$ do not fall within this trend. Typically large deviations in Hammett plots would indicate a change in mechanism or a change in the RDS $;{ }^{57,58}$ however, VTNA of $\left(p-\mathrm{F}_{3} \mathrm{COPh}\right)_{2} \mathrm{~N}_{2}$ showed an identical rate equation to the parent azobenzene. Due to the complexity of this reaction and the fact that NR species are involved in many steps leading up to the rate-determining step, it is difficult to determine the cause of this large deviation for strongly EWGs. 
To further investigate the ability of the diazene to affect the reaction rates, we compared four different ortho-substituted diazenes ( $\mathrm{H}, \mathrm{Me}, \mathrm{Et}$, and $i$-Pr), yielding the Taft plot shown in Figure 17 (bottom). Changing from $\mathrm{H}$ to Me causes a large decrease in rate but further increases the yield with only moderate additional slowdown. As was the case in the azobenzene Hammett, the overall decrease in rate is most likely due to increased steric bulk at the metal center inhibiting alkyne coordination events such as [2+2] cycloaddition and second insertion.

\title{
4. CONCLUSION
}

In conclusion, experiment and theory have shown that Ti-catalyzed [2+2+1] synthesis of pyrroles from alkynes and aryl diazenes proceeds through a unique electrocyclic reductive elimination mechanism. The crux of this mechanism is that low valent $\mathrm{Ti}^{\mathrm{II}}$ intermediates can be stabilized both through backdonation into the reaction products and by solvent effects. In all cases, second alkyne insertion into an titanacyclobutene is rate determining, although complex equilibria prior to the rate-determining step can significantly alter the reaction rate and selectivity. Importantly, computational analysis has allowed us to separate out the stereoelectronic effects that influence reaction selectivity in each step involving alkyne reactivity $([2+2]$ cycloaddition and 1,2-insertion), which will allow for the new development of ligands and catalysts capable of controlling regioselectivity of multisubstituted pyrrole synthesis. Additionally, a key feature of this reaction is that there is no single reaction component that is critical in stabilizing intermediates or transition states throughout the catalytic cycle, indicating that it should be possible to translate this type of reactivity beyond simple pyrrole synthesis and into more broad classes of oxidative catalysis.

\section{Supplementary Material}

Refer to Web version on PubMed Central for supplementary material.

\section{ACKNOWLEDGMENTS}

\begin{abstract}
Financial support was provided by the University of Minnesota (start-up funds, Doctoral Dissertation Fellowship to Z.W.D.-G.), the National Institutes of Health (1R35GM119457), and the Alfred P. Sloan Foundation (I.A.T. is a 2017 Sloan Fellow). Equipment for the Chemistry Department NMR facility was supported through a grant from the National Institutes of Health (S10OD011952) with matching funds from the University of Minnesota. We acknowledge the Minnesota Supercomputing Institute (MSI) at the University of Minnesota and the National Energy Research Scientific Computing Center (NERSC), a DOE Office of Science User Facility supported by the Office of Science of the U.S. Department of Energy under Contract No. DE-AC02-05CH11231, for providing resources that contributed to the results reported within this paper.
\end{abstract}

\section{REFERENCES}

(1). Hunt A Element Recovery and Sustainability; RSC Publishing: Cambridge, 2013.

(2). Odom A; McDaniel TJ Acc. Chem. Res 2015, 48, 2822. [PubMed: 26295382]

(3). Chirik P; Morris R Acc. Chem. Res 2015, 48, 2495-2495. [PubMed: 26370392]

(4). Rodriguez-Ruiz V; Carlino R; Bezzenine-Lafollee S; Gil R; Prim D; Schulz E; Hannedouche J Dalton Trans 2015, 44, 12029-12059. [PubMed: 25803322]

(5). Davis-Gilbert ZW; Tonks IA Dalton Trans 2017, 46, 11522-11528. [PubMed: 28795719]

(6). Gilbert ZW; Hue RJ; Tonks IA Nat. Chem 2016, 8, 63. [PubMed: 26673265] 
(7). (a) Müller TE; Hultzsch KC; Yus M; Foubelo F; Tada M Chem. Rev 2008, 108, 3795-3892 and references cited therein. [PubMed: 18729420] (b)Clough BA; Mellino S; Protchenko AV; Slusarczyk M; Stevenson LC; Blake MP; Xie B; Clot E; Mountford P Inorg. Chem 2017, 56, 10794. [PubMed: 28836774]

(8). Ryken SA; Schafer LL Acc. Chem. Res 2015, 48, 2576-2586. [PubMed: 26247696]

(9). Odom AL; McDaniel TJ Acc. Chem. Res 2015, 48, 2822-2833. [PubMed: 26295382]

(10). Guo J; Deng X; Song C; Lu Y; Qu S; Dang Y; Wang Z-X Chem. Sci 2017, 8 (3), 2413-2425. [PubMed: 28451348]

(11). Knizia GJ Chem. Theory Comput 2013, 9 (11), 4834-4843.

(12). Knizia G; Klein JEMN Angew. Chem., Int. Ed 2015, 54 (18), 5518-5522.

(13). (a) Glendening ED; Landis CR; Weinhold F J. Comput. Chem 2013, 34 (16), 1429-1437. [PubMed: 23483590] (b)Weinhold F; Landis CR: Valency and Bonding: A Natural Bond Orbital Donor-Acceptor Perspective; Cambridge University Press: Cambridge, 2005.

(14). Whitesides GM; Ehmann WJ J. Am. Chem. Soc 1970, 92, 5625-5640.

(15). Blake AJ; Collier PE; Dunn SC; Li W-S; Mountford P; Shishkin OV J. Chem. Soc., Dalton Trans 1997, 0, 1549-1558.

(16). Frisch MJ; Trucks GW; Schlegel HB; Scuseria GE; Robb MA; Cheeseman JR; Scalmani G; Barone V; Mennucci B; Petersson GA; Nakatsuji H; Caricato M; Li X; Hratchian HP; Izmaylov AF; Bloino J; Zheng G; Sonnenberg JL; Hada M; Ehara M; Toyota K; Fukuda R; Hasegawa J; Ishida M; Nakajima T; Honda Y; Kitao O; Nakai H; Vreven T; Montgomery JA Jr.; Peralta JE; Ogliaro F; Bearpark M; Heyd JJ; Brothers E; Kudin KN; Staroverov VN; Kobayashi R; Normand J; Raghavachari K; Rendell A; Burant JC; Iyengar SS; Tomasi J; Cossi M; Rega N; Millam JM; Klene M; Knox JE; Cross JB; Bakken V; Adamo C; Jaramillo J; Gomperts R; Stratmann RE; Yazyev O; Austin AJ; Cammi R; Pomelli C; Ochterski JW; Martin RL; Morokuma K; Zakrzewski VG; Voth GA; Salvador P; Dannenberg JJ; Dapprich S; Daniels AD; Farkas O; Foresman JB; Ortiz JV; Cioslowski J; Fox DJ Gaussian 09, Revision B.01; Gaussian, Inc.: Wallingford, CT, 2009.

(17). Zhao Y; Truhlar DG Theor. Chem. Acc 2008, 120 (1), 215-241.

(18). Krishnan R; Binkley JS; Seeger R; Pople JA J. Chem. Phys 1980, 72 (1), 650-654.

(19). Marenich AV; Cramer CJ; Truhlar DG J. Phys. Chem. B 2009, 113 (18), 6378-6396. [PubMed: 19366259]

(20). Werner HJ; Knowles PJ; Knizia G; Manby FR; Schütz M Wiley Interdisciplinary Reviews: Computational Molecular Science 2012, 2 (2), 242-253.

(21). Weigend F; Ahlrichs R Phys. Chem. Chem. Phys 2005, 7 (18), 3297-3305. [PubMed: 16240044]

(22). Webster AJ; Mueller CM; Foegen NP; Sit PHL; Speetzen ED; Cunningham DW; D’Acchioli JS Polyhedron 2016, 114, 128-132

(23). Blackmond DJ Angew. Chem., Int. Ed 2005, 44, 4302-4320.

(24). Blackmond DG J. Am. Chem. Soc 2015, 137, 10852-10866. [PubMed: 26285166]

(25). Burés J Angew. Chem., Int. Ed 2016, 55, 2028-2031.

(26). Burés J Angew. Chem., Int. Ed 2016, 55, 16084-16087.

(27). Rosner T; Le Bars J; Pfaltz A; Blackmond DG J. Am. Chem. Soc 2001, 123, 1848-1855. [PubMed: 11456804]

(28). Hill DE; Pei Q-I; Zhang E; Gage JR; Yu J-Q; Blackmond DG ACS Catal 2018, 8, 1528-1531.

(29). (a) Bennett JL; Wolczanski PT J. Am. Chem. Soc 1994, 116, 2179-2180.(b)Nielson AJ; Glenny MW; Rickard CEF J. Chem. Soc., Dalton Trans 2001, 232-239.

(30). Zuckerman RL; Krska SW; Bergman RB J. Am. Chem. Soc 2000, 122, 751-761. [PubMed: 16636698]

(31). Pohlki F; Doye S Angew. Chem., Int. Ed 2001, 40, 2305-2308.

(32). Johnson JS; Bergman BG J. Am. Chem. Soc 2001, 123, 2923-2924. [PubMed: 11456996]

(33). Straub BF; Bergman RG Angew. Chem., Int. Ed 2001, 40, 4632-4635.

(34). Esteruelas MA; López AM; Mateo AC; Oñate E Organometallics 2006, 25, 1448-1460.

(35). Streuff J; Himmel D; Younas SL Dalton Trans 2018, 47, 5072. [PubMed: 29561012] 
(36). See XY; Beaumier EP; Davis-Gilbert ZW; Dunn PL; Larsen JA; Pearce AJ; Wheeler TA; Tonks IA Organometallics 2017, 36, 1388-1390.

(37). Laidler KJ; Tweedale A In Advances in Chemical Physics; Hirschfelder JO, Henderson D, Eds.; Wiley, 2007.

(38). Kramers HA Physica 1940, 7, 284-304.

(39). Aullón G; Alvarez S Theor. Chem. Acc 2009, 123 (1), 67-73.

(40). Vinogradov MG; Turova OV; Zlotin SG Org. Biomol. Chem 2017, 15, 8245-8269 and references cited therein. [PubMed: 28960012]

(41). Negishi E; Takahashi T Acc. Chem. Res 1994, 27, 124-130.

(42). Epstein OL; Savchenko AI; Kulinkovich OG Russ. Chem. Bull 2000, 49, 378-380.

(43). Siebeneicher H; Doye SJ Prakt. Chem 2000, 342, 102-106.

(44). Kulinkovich OG; Sviridov SV; Vasilevski DA Synthesis 1991, 1991, 234.

(45). Davis-Gilbert ZW; Yao LJ; Tonks IA J. Am. Chem. Soc 2016, 138, 14570. [PubMed: 27790910]

(46). Hicks FA; Kablaoui NM; Buchwald SL J. Am. Chem. Soc 1999, 121, 5881-5898.

(47). Hicks FA; Buchwald SLJAm. Chem. Soc 1999, 121, 7026-7033.

(48). Marenich AV; Cramer CJ; Truhlar DG J. Phys. Chem. B 2009, 113, 4538-4543. [PubMed: 19253989]

(49). White DP; Anthony JC; Oyefeso AO J. Org. Chem 1999, 64, 7707-7716.

(50). Eliel EL, Wilen SH; Mander LN Stereochemistry of Organic Compounds; Wiley: New York, 1994.

(51). Hansch C; Leo A; Taft RW Chem. Rev 1991, 91, 165-195.

(52). Chiu H-C; Tonks IA Angew. Chem., Int. Ed 2018, 57, 6090-6094.

(53). Difranco SA; Maciulis NA; Staples RJ; Odom AL; Batrice RJ Inorg. Chem 2012, 51, 1187-1200. [PubMed: 22200335]

(54). Bemowski RD; Singh AK; Bajorek BJ; Deporre Y; Odom AL Dalton Trans 2014, 43, 12299_ 12305. [PubMed: 24986246]

(55). Billow BS; McDaniel TJ; Odom AL Nat. Chem 2017, 9, 837-842. [PubMed: 28837168]

(56). Falivene L; Credendino R; Poater A; Petta A; Serra L; Oliva R; Scarano V; Cavallo L Organometallics 2016, 35, 2286.

(57). Schreck JO J. Chem. Educ 1971, 48, 103-107.

(58). Bergon M; Calmon J-P Tetrahedron Lett 1981, 22, 937-940. 

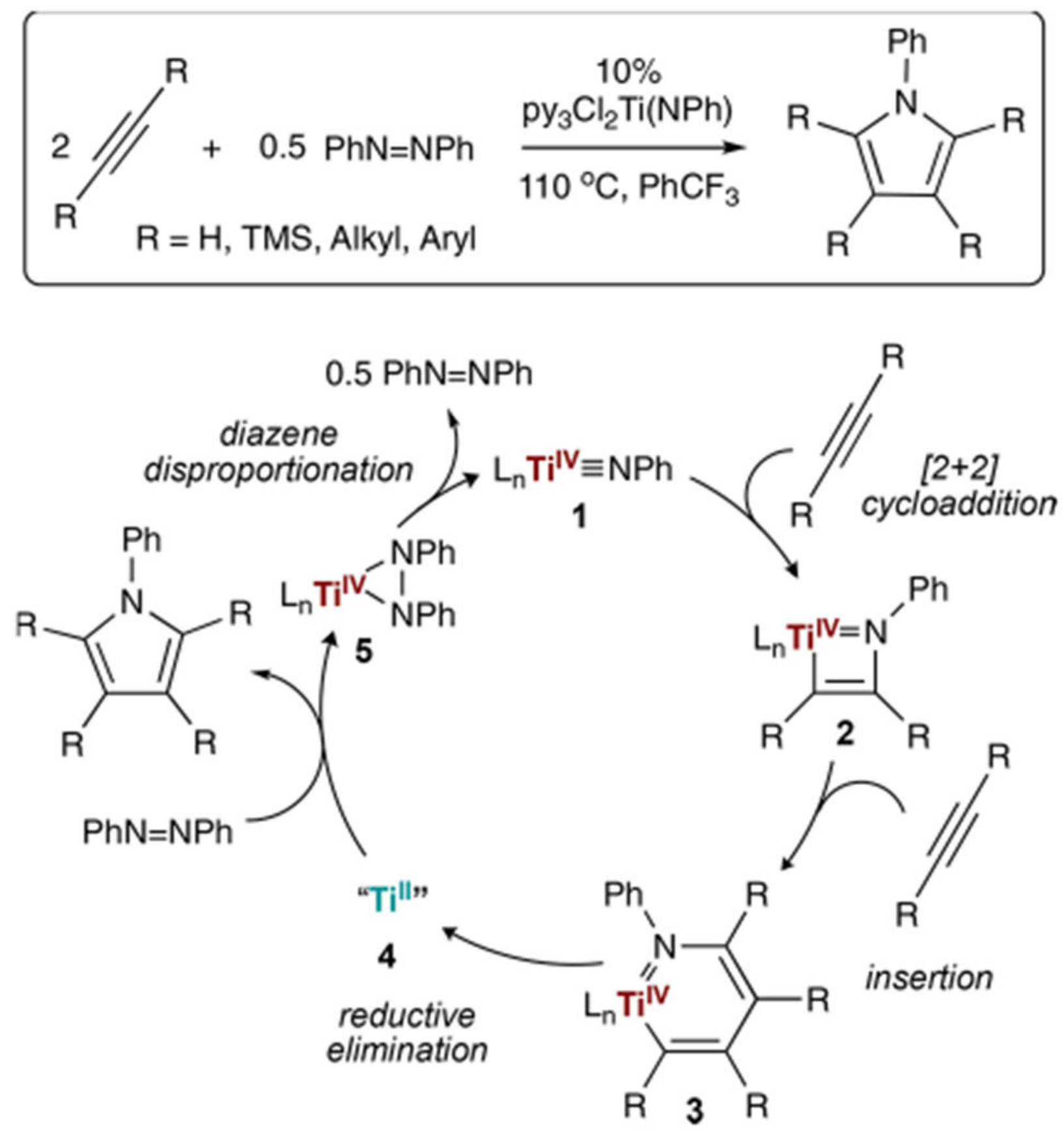

Figure 1.

Proposed mechanism of Ti-catalyzed formal $[2+2+1]$ cycloaddition of alkynes with azobenzene. 

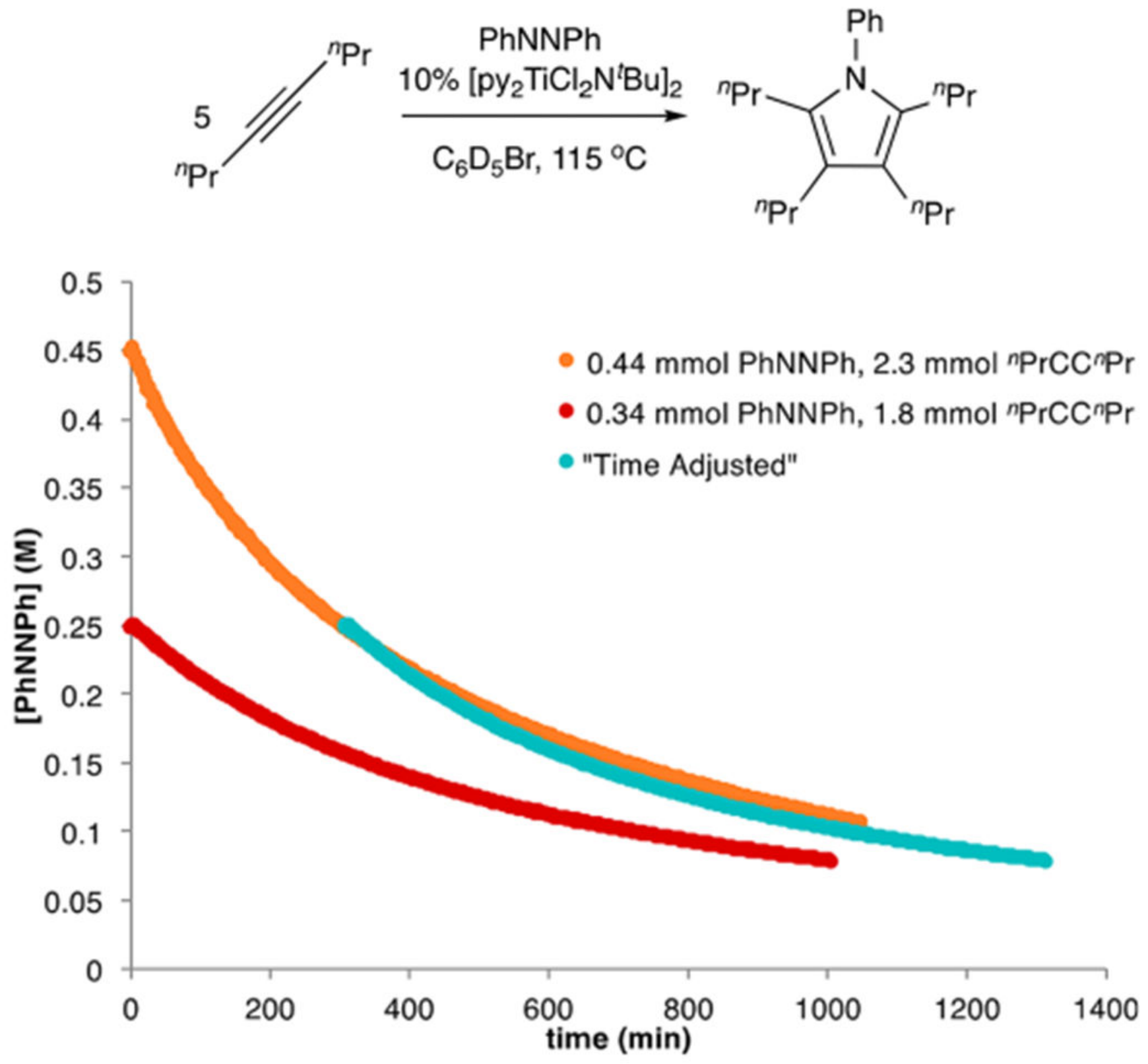

Figure 2.

Same-excess experiments of $\left[\mathrm{py}_{2} \mathrm{TiCl}_{2} \mathrm{~N}^{t} \mathrm{Bu}\right]_{2}$-catalyzed pyrrole formation from 4-octyne and azobenzene indicate no catalyst decomposition or product inhibition. Reaction conditions for experiment 1: $0.44 \mathrm{mmol}$ of PhNNPh and $2.3 \mathrm{mmol}$ of 4-octyne were reacted with $0.04 \mathrm{mmol}$ of $\left[\mathrm{py}_{2} \mathrm{TiCl}_{2} \mathrm{~N}^{t} \mathrm{Bu}\right]_{2}$ in $0.5 \mathrm{~mL}$ of $\mathrm{C}_{6} \mathrm{D}_{5} \mathrm{Br}$ at $115^{\circ} \mathrm{C}$. Reaction conditions for experiment 2: $0.34 \mathrm{mmol}$ of $\mathrm{PhNNPh}$ and $1.77 \mathrm{mmol}$ of 4-octyne were reacted with 0.04 mmol of $\left[\mathrm{py}_{2} \mathrm{TiCl}_{2} \mathrm{~N}^{t} \mathrm{Bu}\right]_{2}$ in $0.5 \mathrm{~mL}$ of $\mathrm{C}_{6} \mathrm{D}_{5} \mathrm{Br}$ at $115^{\circ} \mathrm{C}$. 

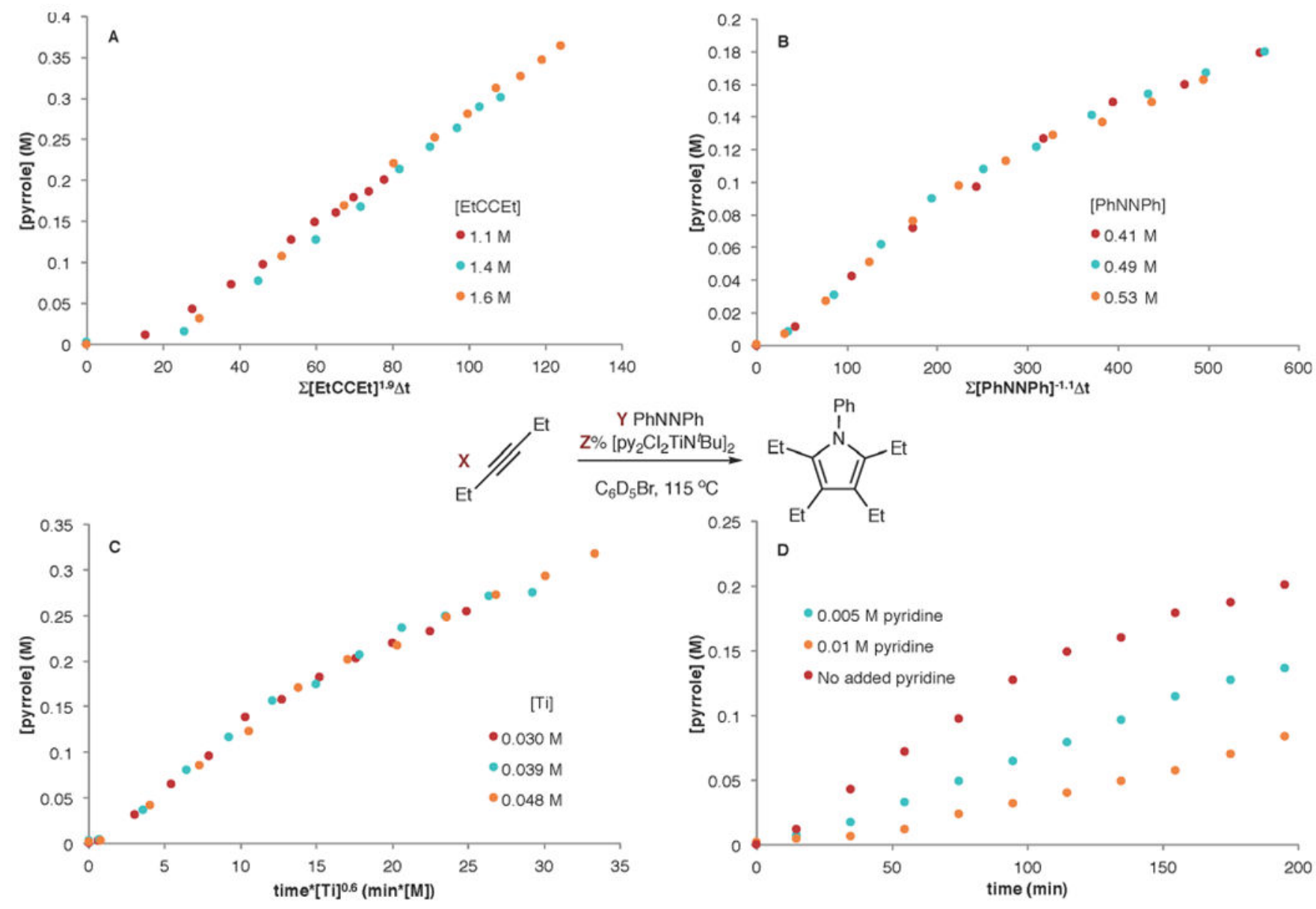

$Y \mathrm{PhNNPh}$

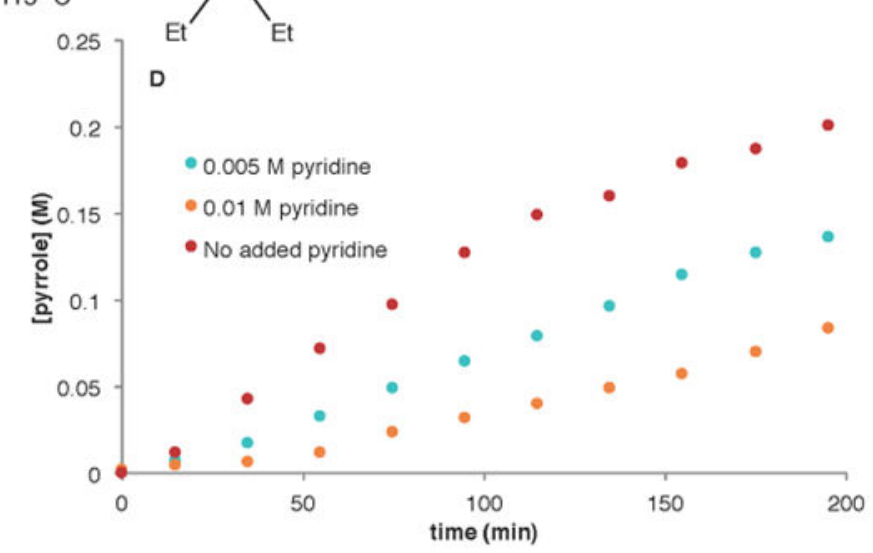

Figure 3.

Best-fit rate law determination of $\left[\mathrm{py}_{2} \mathrm{TiCl}_{2} \mathrm{~N}^{t} \mathrm{Bu}\right]_{2}$-catalyzed pyrrole formation from 3hexyne and azobenzene via variable time normalization analysis (VTNA). Full reaction conditions can be found in Table S1.

J Am Chem Soc. Author manuscript; available in PMC 2019 May 09. 


\section{Also Relevant:}

-Azobenzene inhibition

-Pyridine inhibition
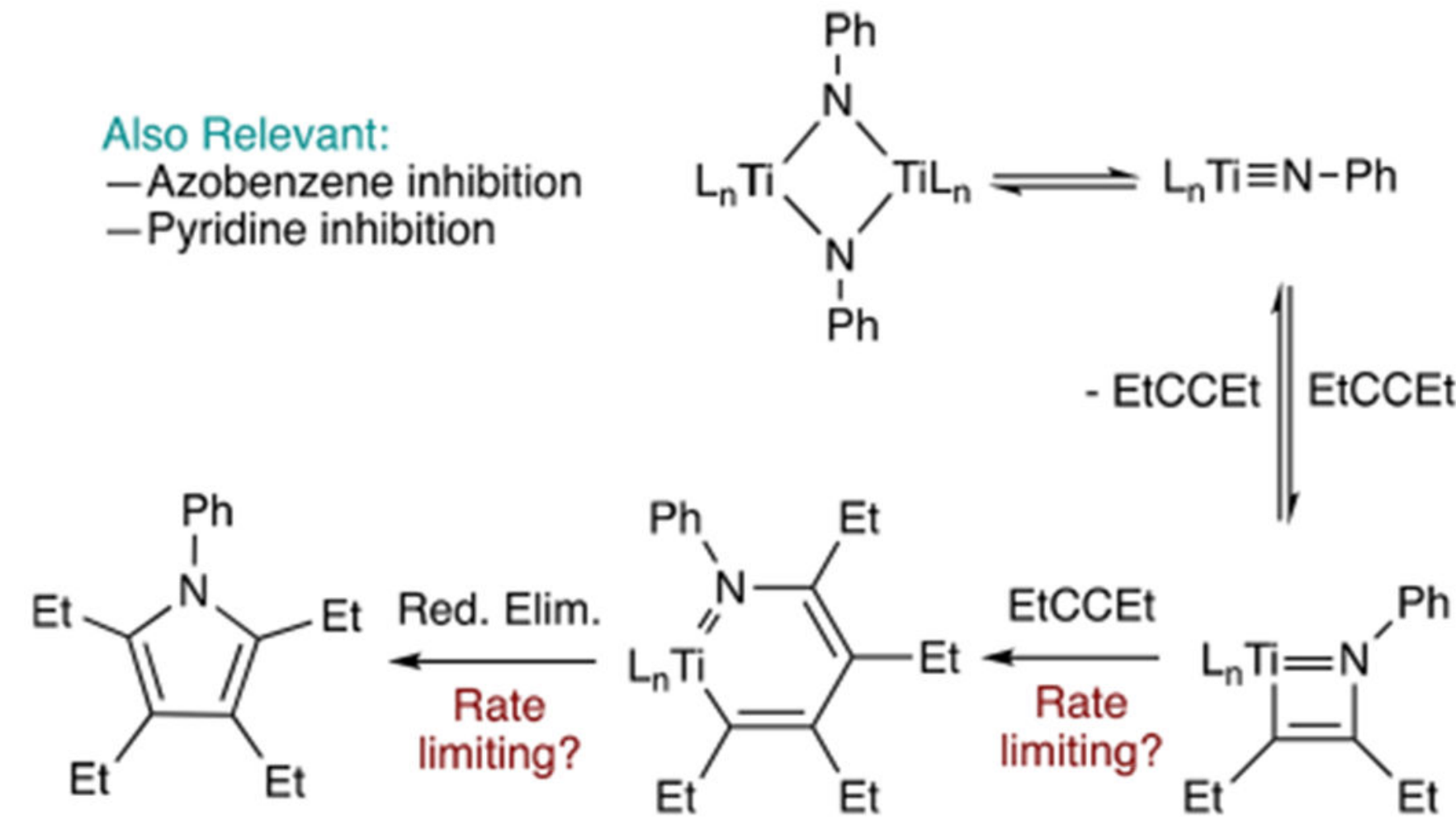

Figure 4.

Kinetically relevant steps of Ti-catalyzed 3-hexyne pyrrole formation proposed from rate law data. 


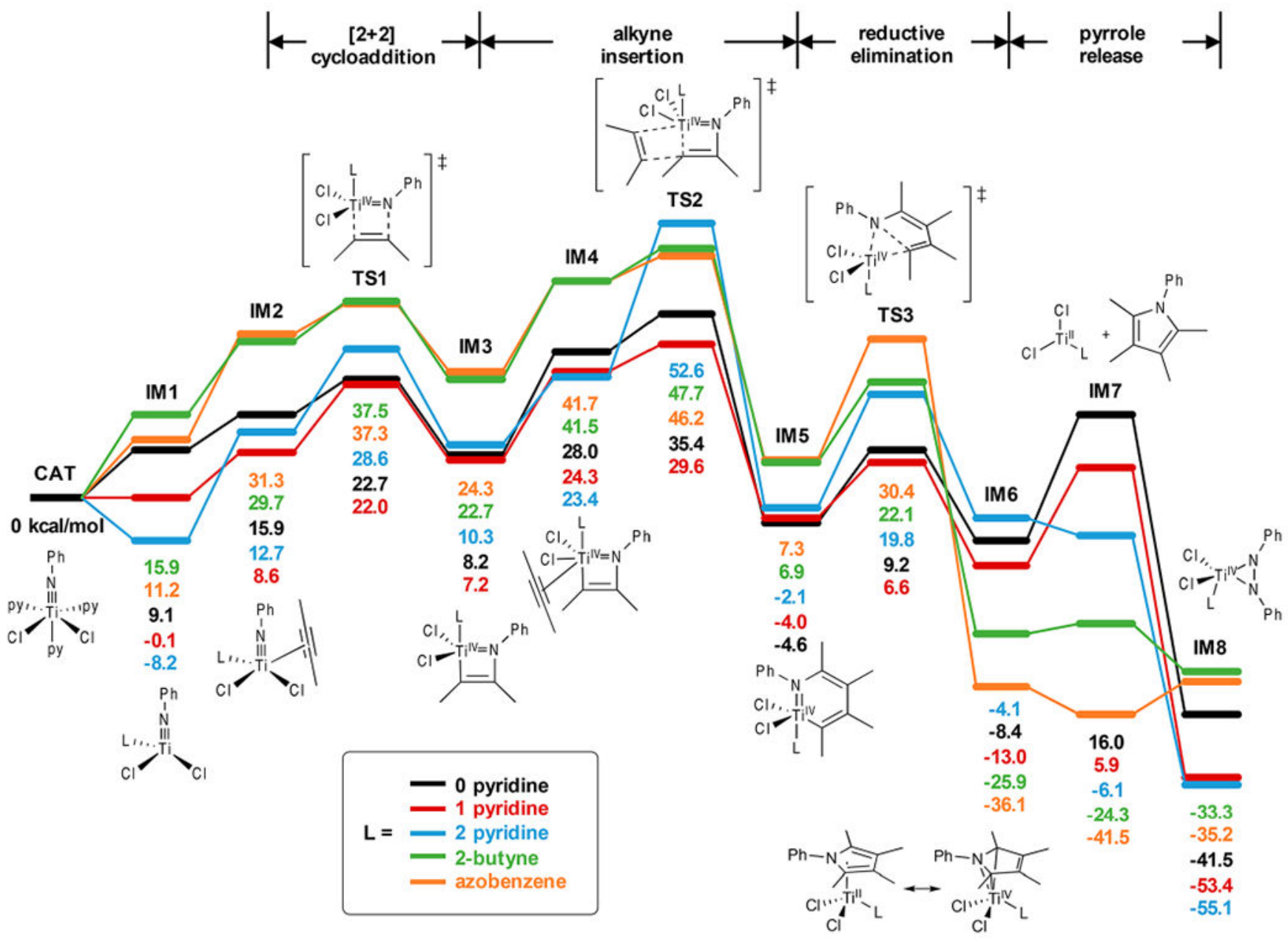

Figure 5.

Free energy profile for the formation of $\mathrm{N}$-phenyltetramethylpyrrole from 2-butyne, azobenzene, and py $\mathrm{TiCl}_{2}(\mathrm{NPh})$. The reaction pathway is calculated using $\mathrm{L}=$ none (black), one pyridine (red), two pyridines (blue), 2-butyne (green), and azobenzene (orange). The geometries for all ligand combinations are provided in the Supporting Information. The free energy profile to close the catalytic cycle from IM8 to $\mathbf{C A T}^{\prime}$ can be found in Figure 11. 


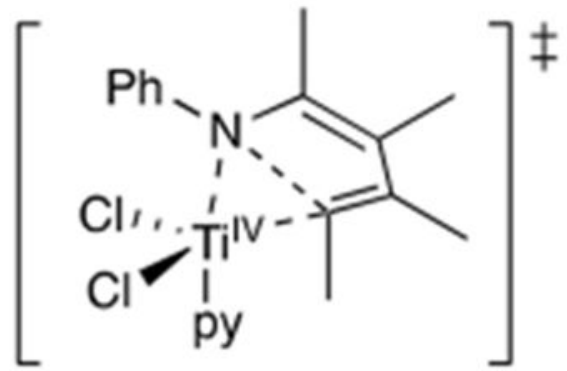

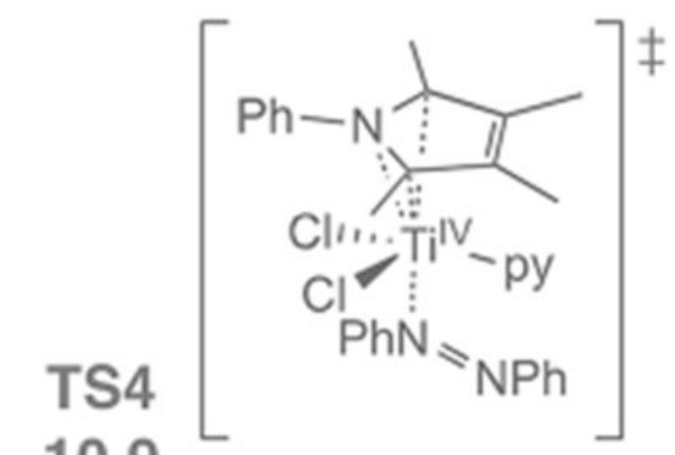

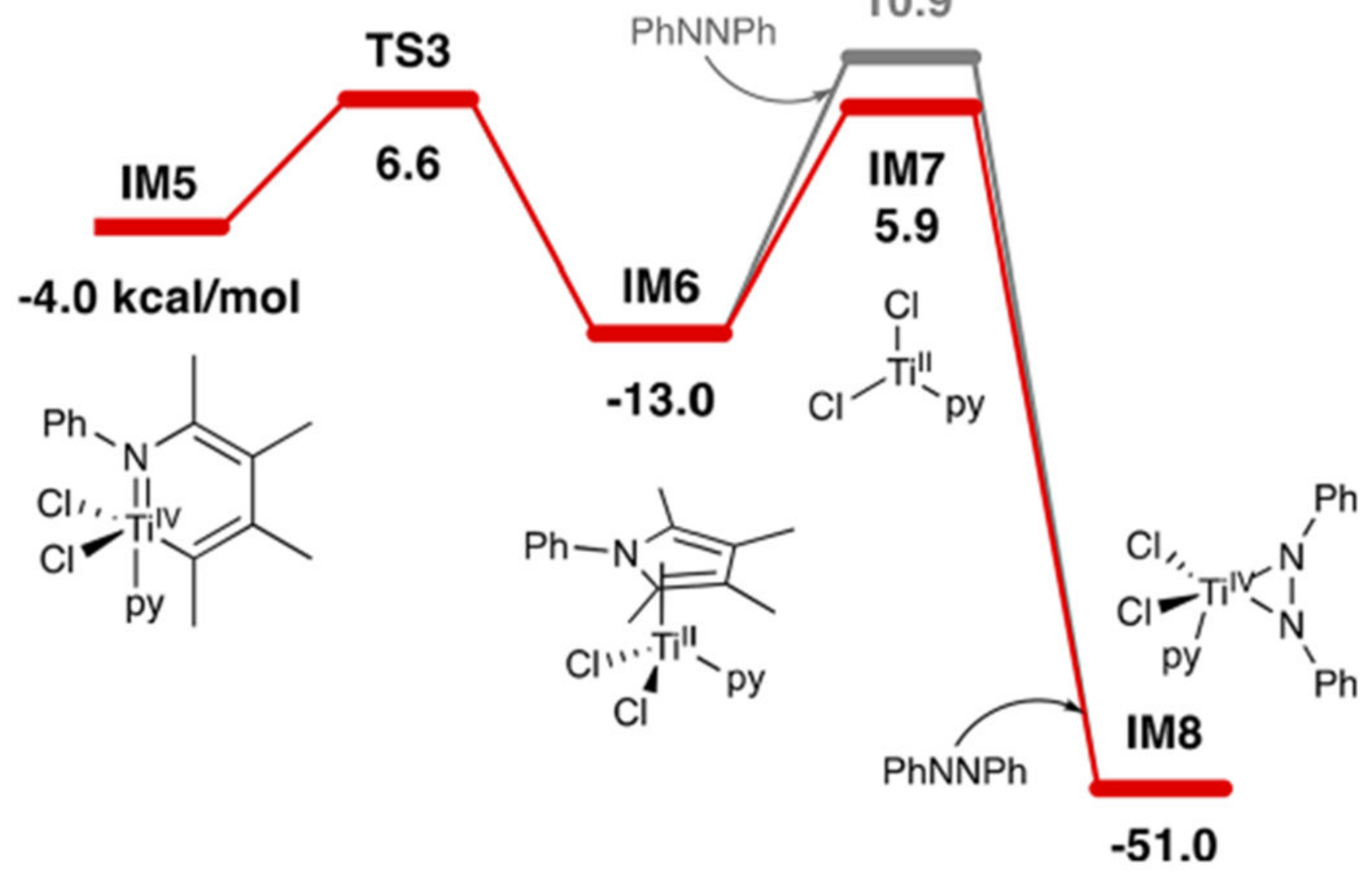

Figure 6.

Comparing the free energy required to dissociate pyrrole from $\mathrm{Ti}^{\mathrm{II}}$ to the transition-state barrier for azobenzene binding to the Ti-pyrrole complex. Direct pyrrole dissociation from $\mathrm{Ti}^{\mathrm{II}}$ in IM6 is the lower energy pathway. 


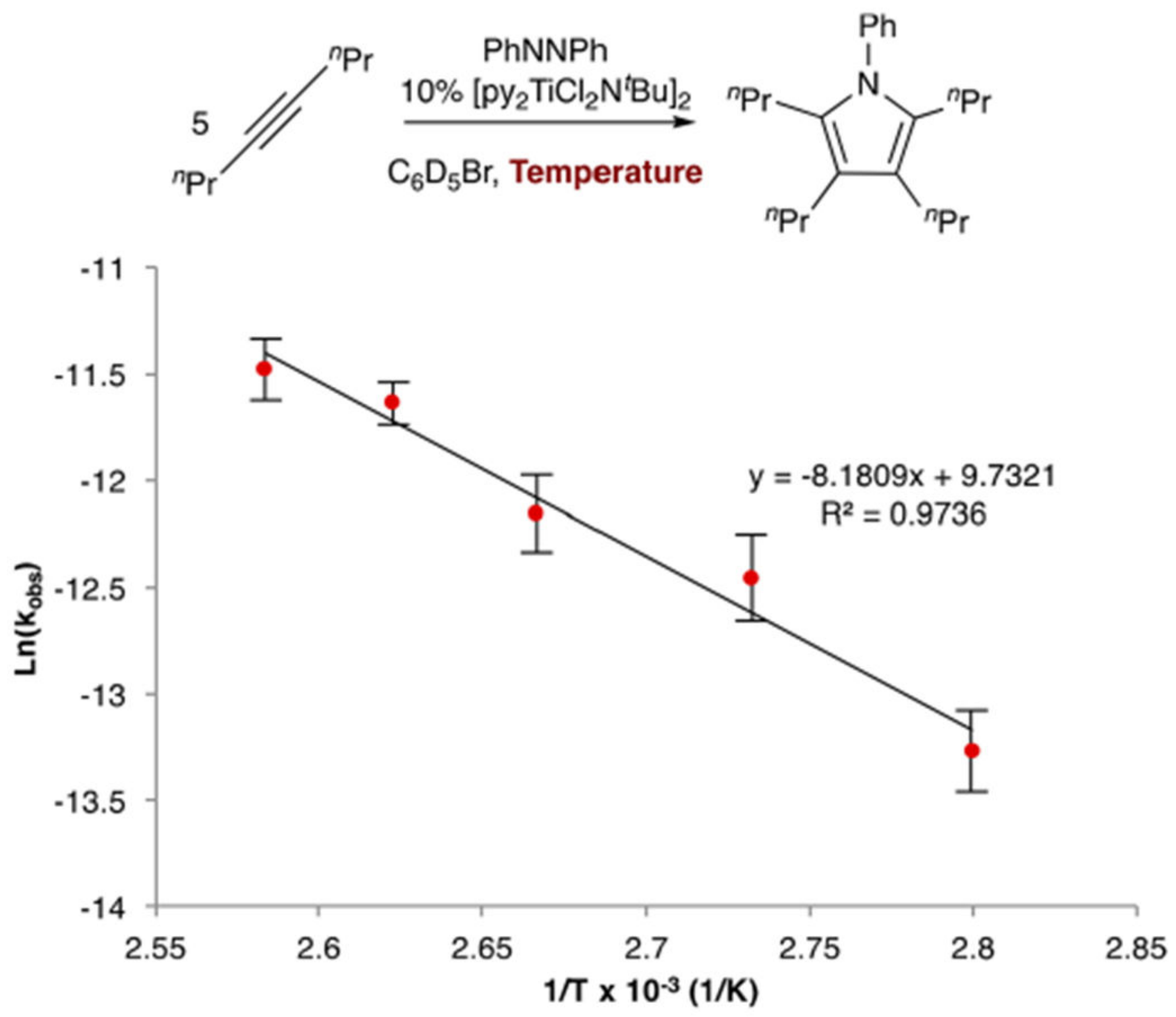

Figure 7.

Arrhenius-like plot of the reaction of 4-octyne with azobenzene catalyzed by $\left[\mathrm{py}_{2} \mathrm{TiCl}_{2} \mathrm{~N}^{t} \mathrm{Bu}\right]_{2}$. Reaction conditions can be found in Table S7. 

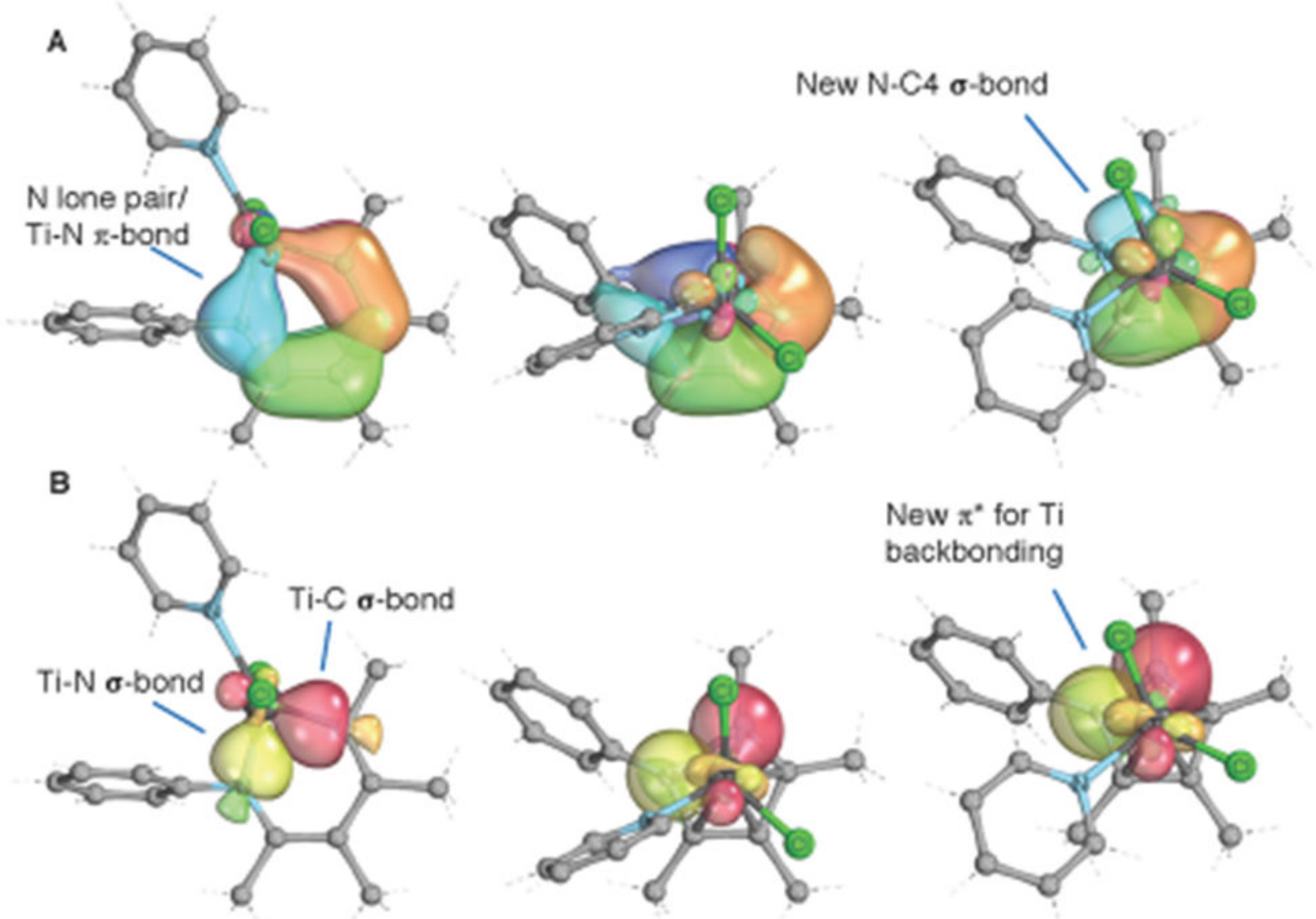

C

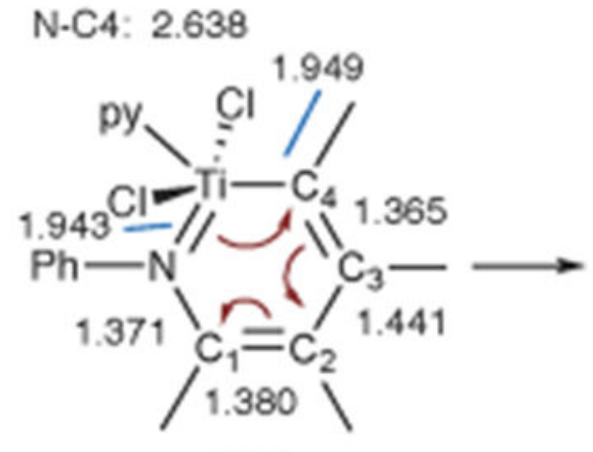

IM5

Ti-N: 1.998

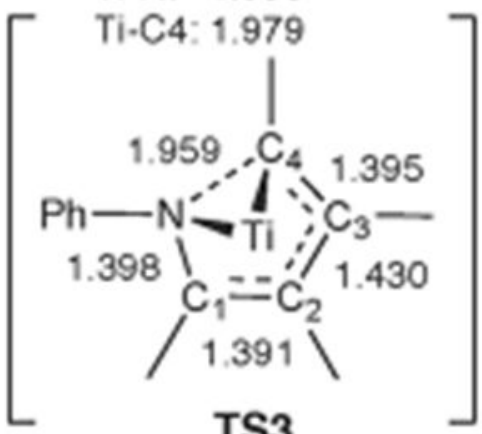

$\mathrm{Ti} \cdot \mathrm{N}: 2.122$

$\ddagger \quad \mathrm{Ti}-\mathrm{C} 4: 2.078$

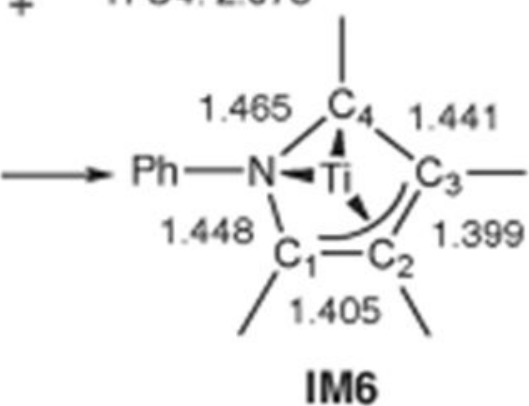

\section{Figure 8.}

IBOs of the reactant (L, IM5), transition state (M, TS3), and product (R, IM6) in the reductive elimination step. IBOs show (A) the lone pair on the $\mathrm{N}$ atom/Ti-N $\pi$-bond in IM5 (blue orbital) rotates and attacks $\mathrm{C} 4$ to form the new $\mathrm{C}-\mathrm{N} \sigma$ bond in an electrocyclic fashion, (B) orbital rotation for $\pi$ backbonding with $\mathrm{Ti}$, and (C) an arrow pushing diagram of the reductive elimination along with calculated bond lengths (in $\AA$ ). 

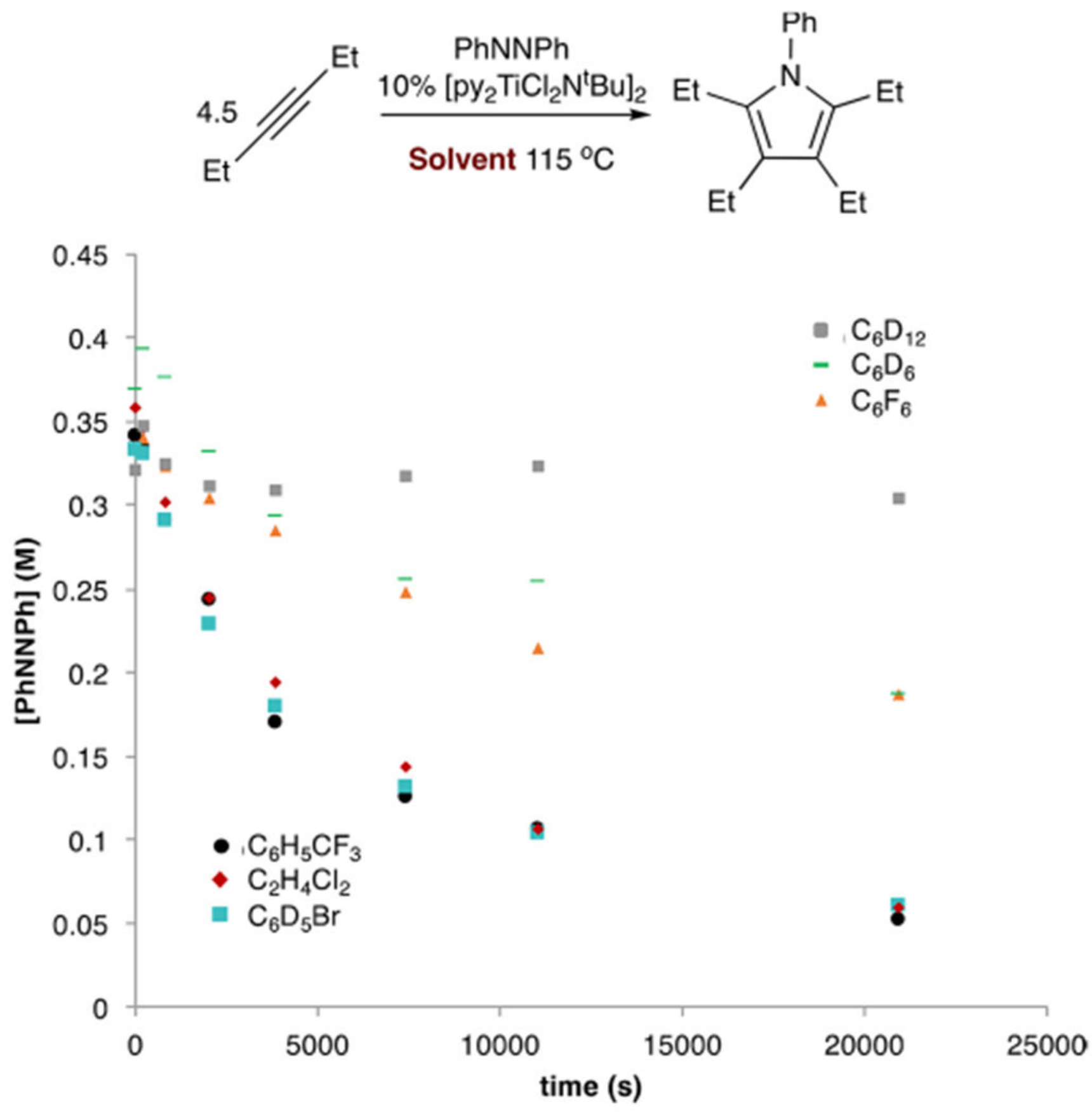

Figure 9.

Solvent screen of $\left[\mathrm{py}_{2} \mathrm{TiCl}_{2} \mathrm{~N}^{t} \mathrm{Bu}\right]_{2}$-catalyzed pyrrole formation from 3-hexyne and azobenzene. Reaction conditions can be found in Figure S34. 

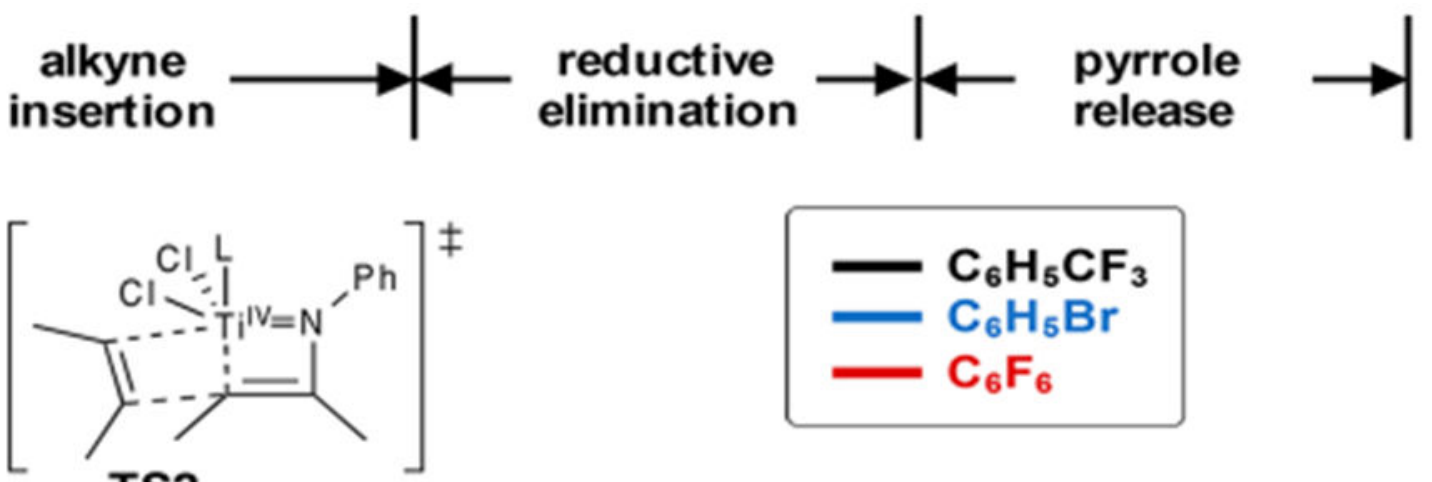

TS2

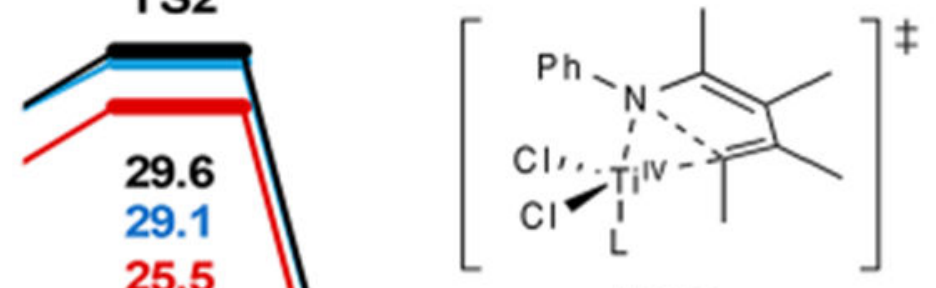

25.5

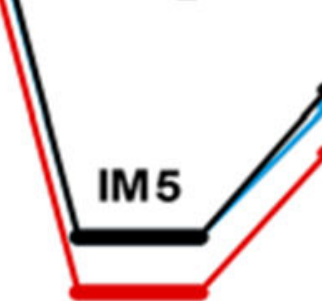

$-4.0$

$-4.0$<smiles>[R6]C1=C(C)N(c2ccccc2)[Y](Cl)(Cl)C(C)=C1C</smiles>

TS3<smiles>CCC</smiles>

CI<smiles>[AlH][AlH]Cl</smiles>

IM7<smiles></smiles>

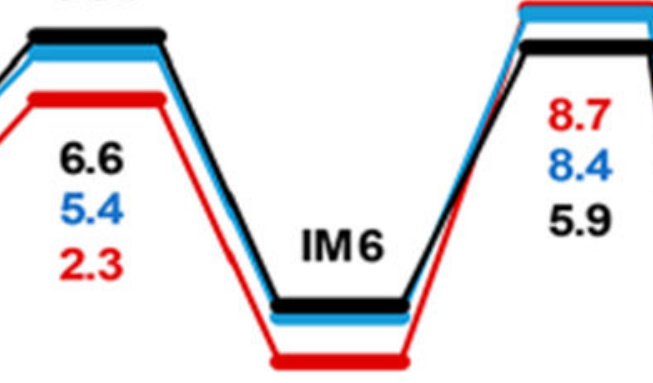

$-13.0$

$-13.5$

$-17.1$<smiles>CCc1c(C)c(C)c([Al](Cl)(Cl)Cl)n1-c1ccccc1</smiles>

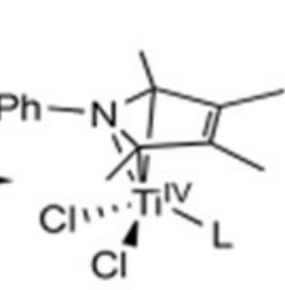<smiles></smiles>

$-50.5$

$-53.4$

$-57.3$

IM 8

Figure 10.

Free energy profile for the alkyne insertion, reductive elimination, and pyrrole release step in $\mathrm{PhCF}_{3}$ (black), $\mathrm{C}_{6} \mathrm{~F}_{6}$ (red), and $\mathrm{C}_{6} \mathrm{D}_{5} \mathrm{Br}$ (blue). 


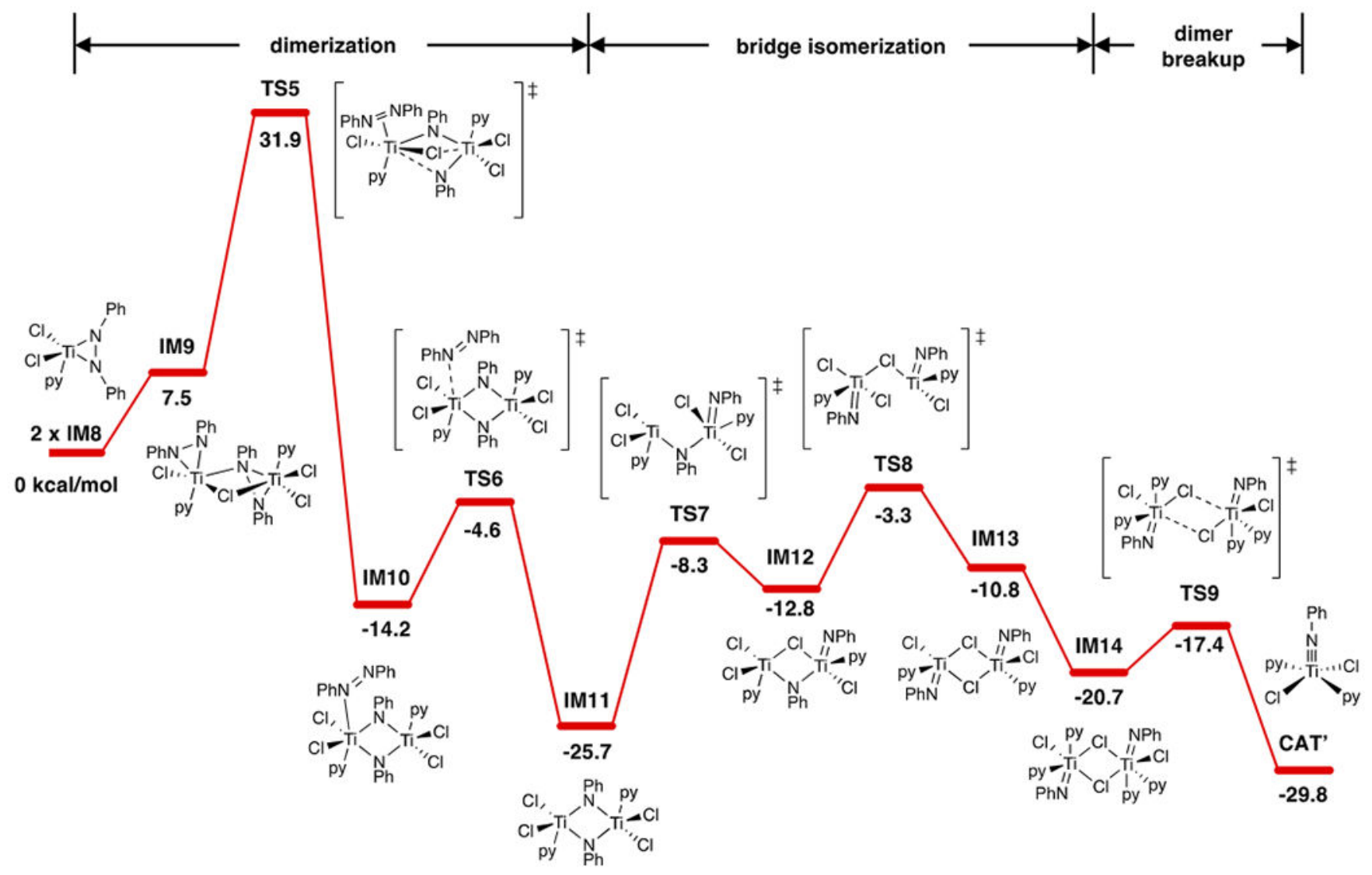

Figure 11.

Free energy profile for the regeneration of the Ti imido catalyst via disproportionation. 

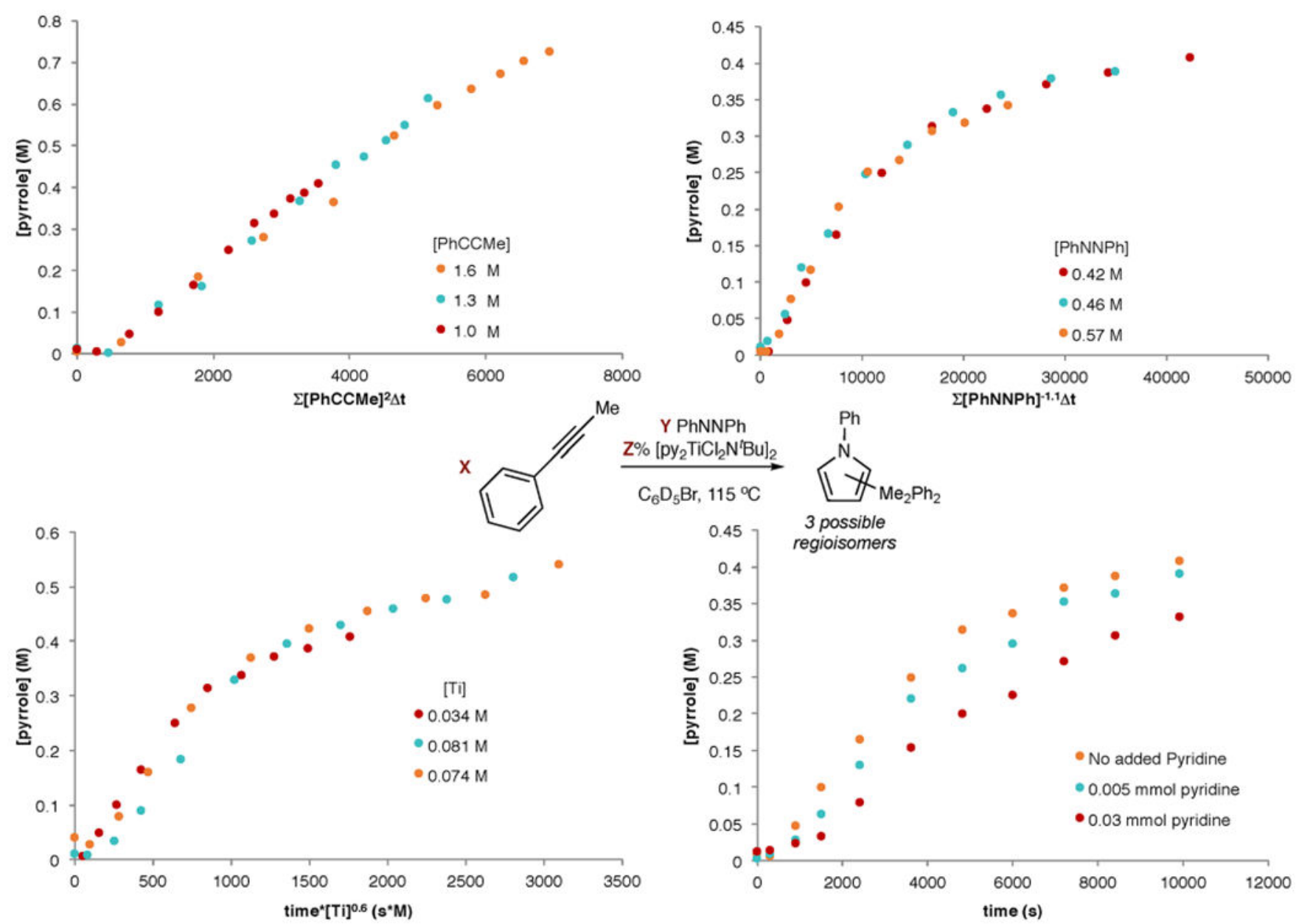

Figure 12.

Best-fit rate law determination of $\left[\mathrm{py}_{2} \mathrm{TiCl}_{2} \mathrm{~N}^{t} \mathrm{Bu}\right]_{2}$-catalyzed pyrrole formation from phenylpropyne and azobenzene via variable time normalization analysis (VTNA). Reaction conditions can be found in Table S3. 


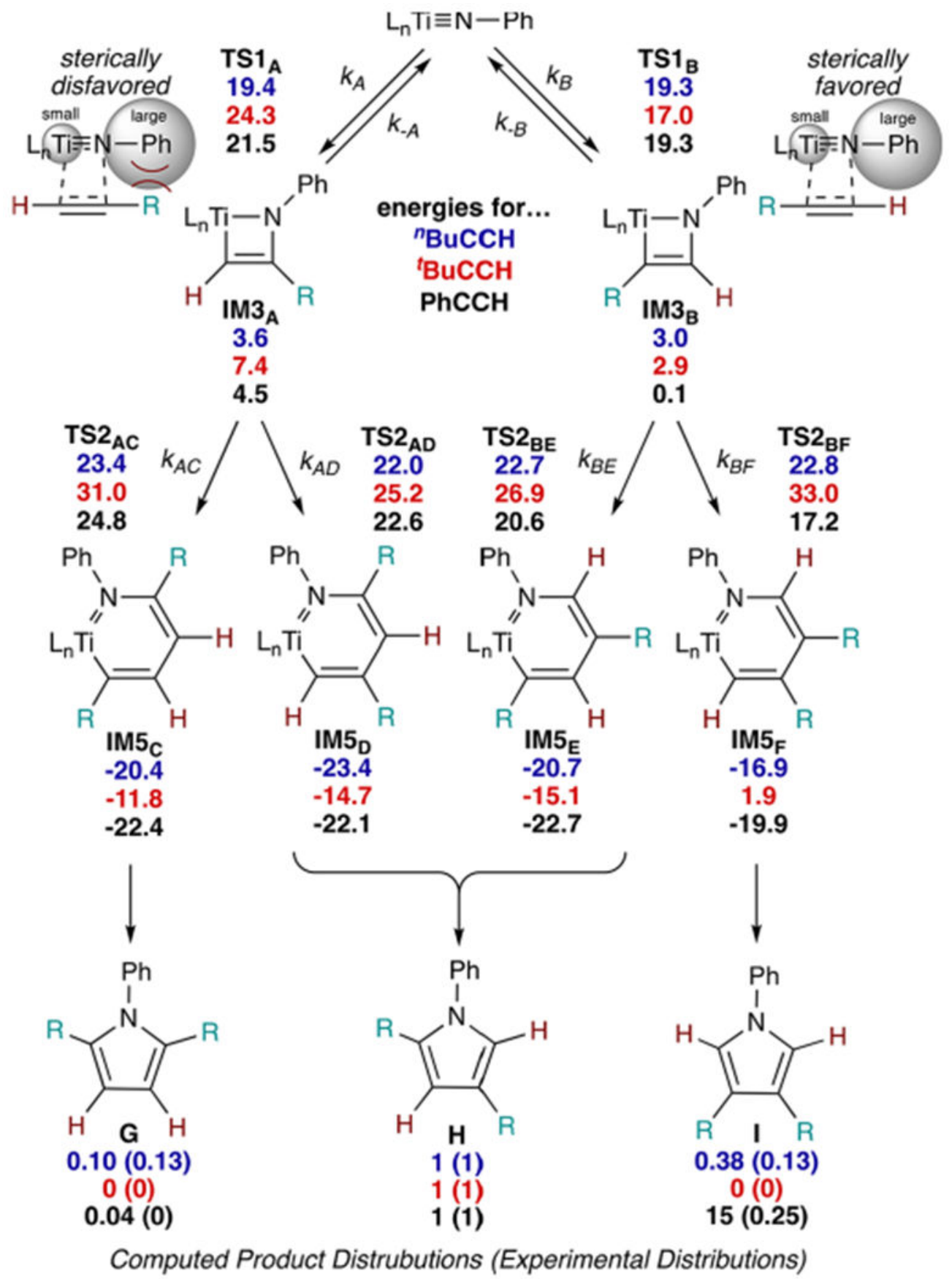

Figure 13.

Reaction pathways leading to three regioisomeric pyrroles from unsymmetrical terminal alkynes. $\mathrm{L}_{n}=\mathrm{pyCl}_{2}$ for all calculated structures. Full details are available in Table S9. Calculated transition state and intermediate energies are presented below each structure. All energies are in $\mathrm{kcal} / \mathrm{mol}$ and reported with respect to $\mathrm{py}_{3} \mathrm{TiCl}_{2}(\mathrm{NPh})=0.0 \mathrm{kcal} / \mathrm{mol}$. Product distributions are standardized against $\mathbf{H}$. Experimental ratios were taken from ref 6 


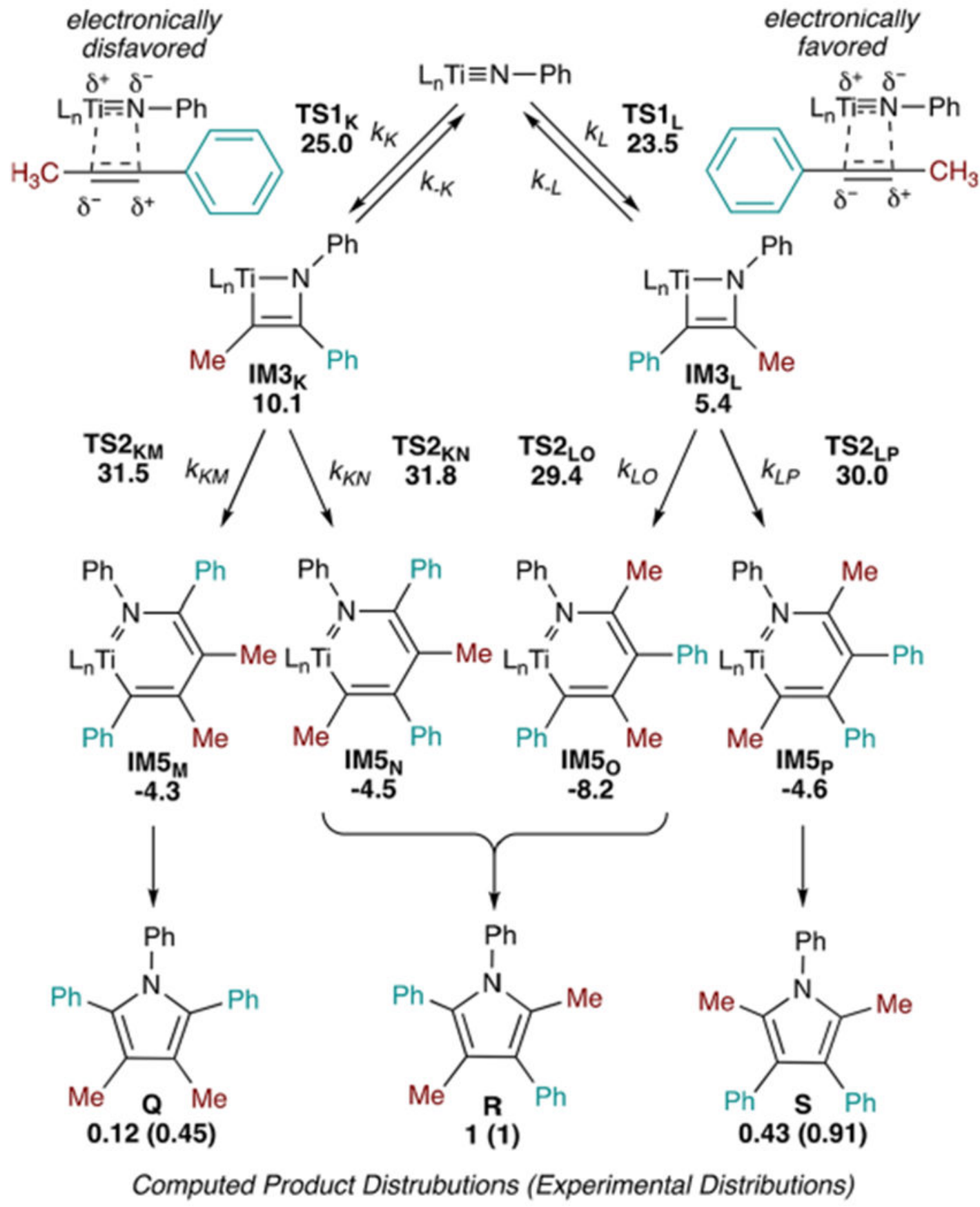

Figure 14.

Reaction pathways leading to three regioisomeric pyrroles from phenylpropyne alkynes. $\mathrm{L}_{n}$ $=\mathrm{pyCl}_{2}$ for all calculated structures. Full details are available in Table $\mathrm{S} 9$. Calculated transition-state and intermediate energies are presented below each structure. All energies are in $\mathrm{kcal} / \mathrm{mol}$ and reported with respect to $\mathrm{py}_{3} \mathrm{TiCl}_{2}(\mathrm{NPh})=0.0 \mathrm{kcal} / \mathrm{mol}$. Product distributions are standardized against R. Experimental ratios were taken from ref 6 . 

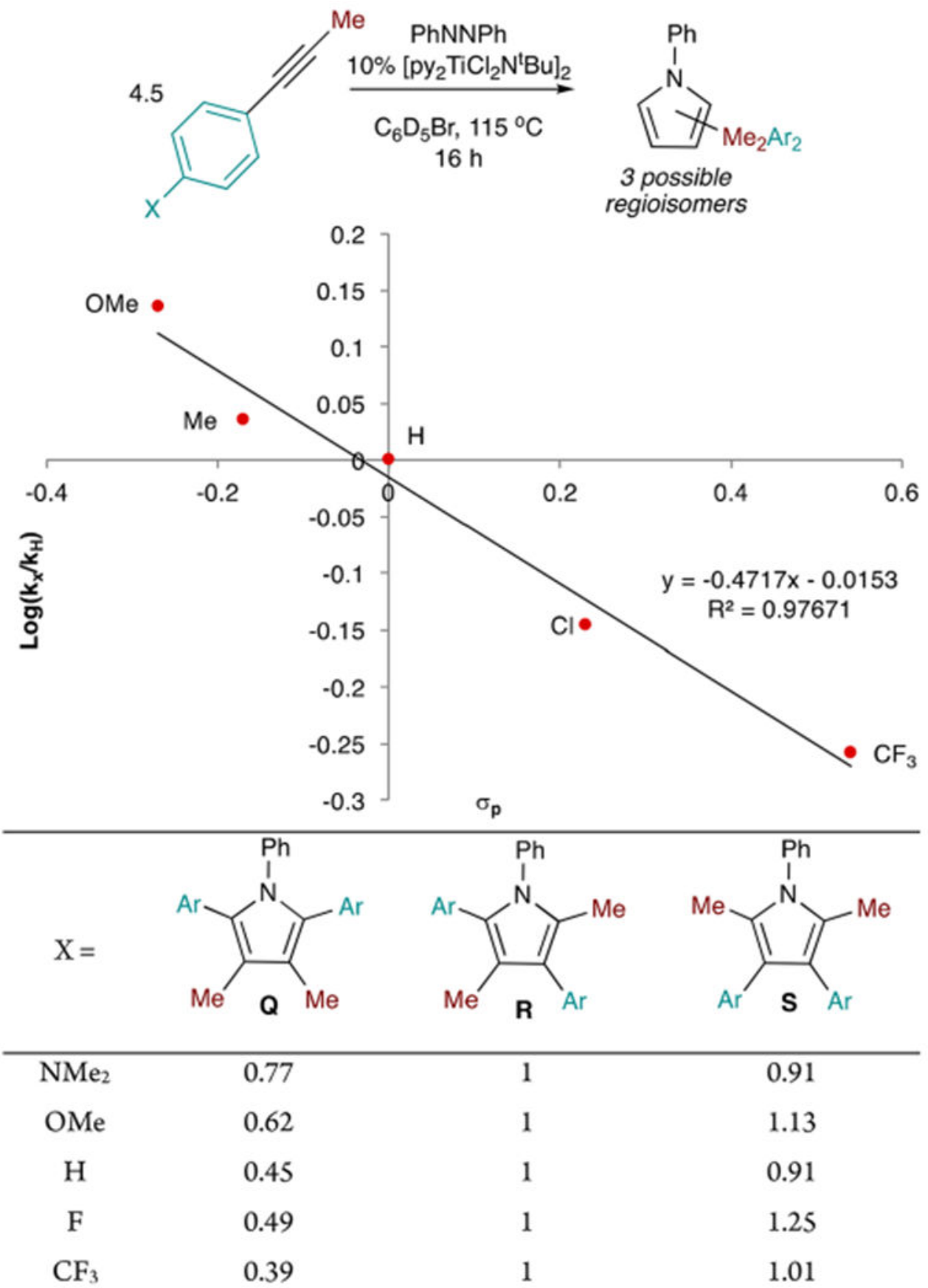

Figure 15.

(Top) Hammett plot of various para-substituted phenylpropynes. (Bottom) product distribution of regioisomers as a fUnction of para-substitution. All product ratios are standardized against $\mathbf{R}$. Reaction conditions are available in Table S5. 

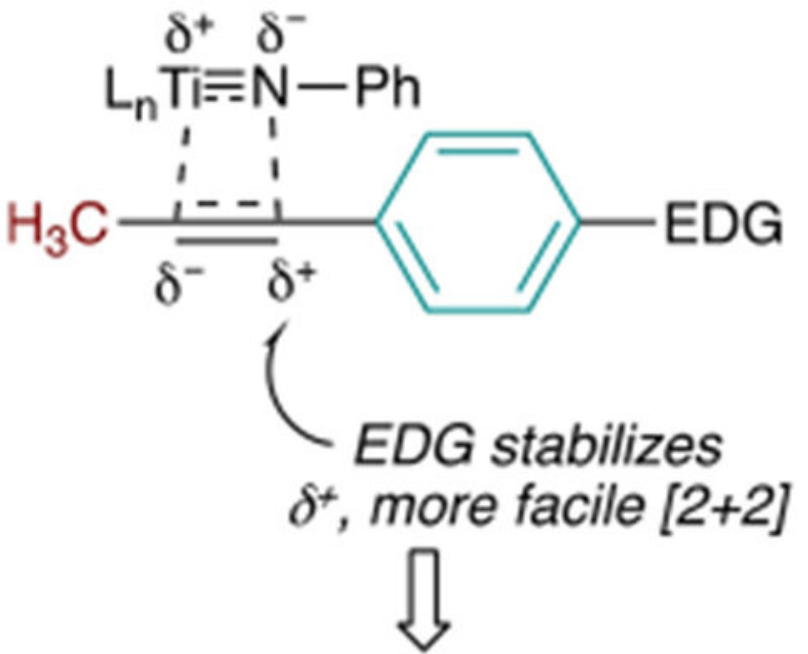

more $\boldsymbol{Q}$

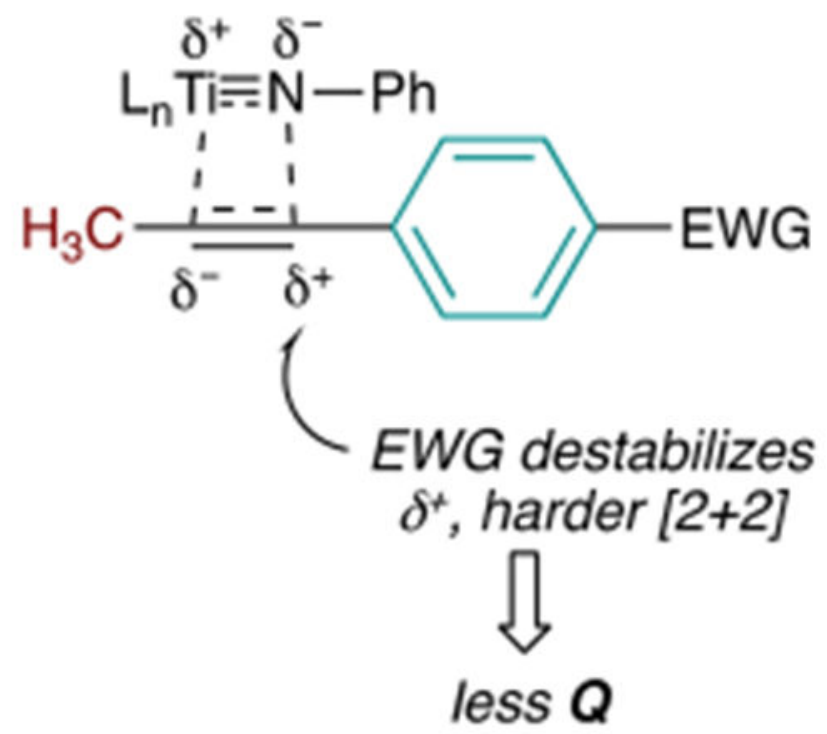

Figure 16.

Partial charge explanation for donor effects in arylpropyne regioselectivity. 


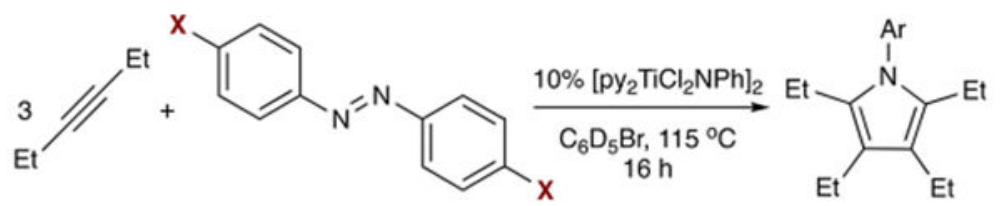

$\mathrm{X}=\mathrm{OMe}, \mathrm{Me}, \mathrm{Et}, \mathrm{H}, \mathrm{F}, \mathrm{Cl}, \mathrm{OCF}_{3}$
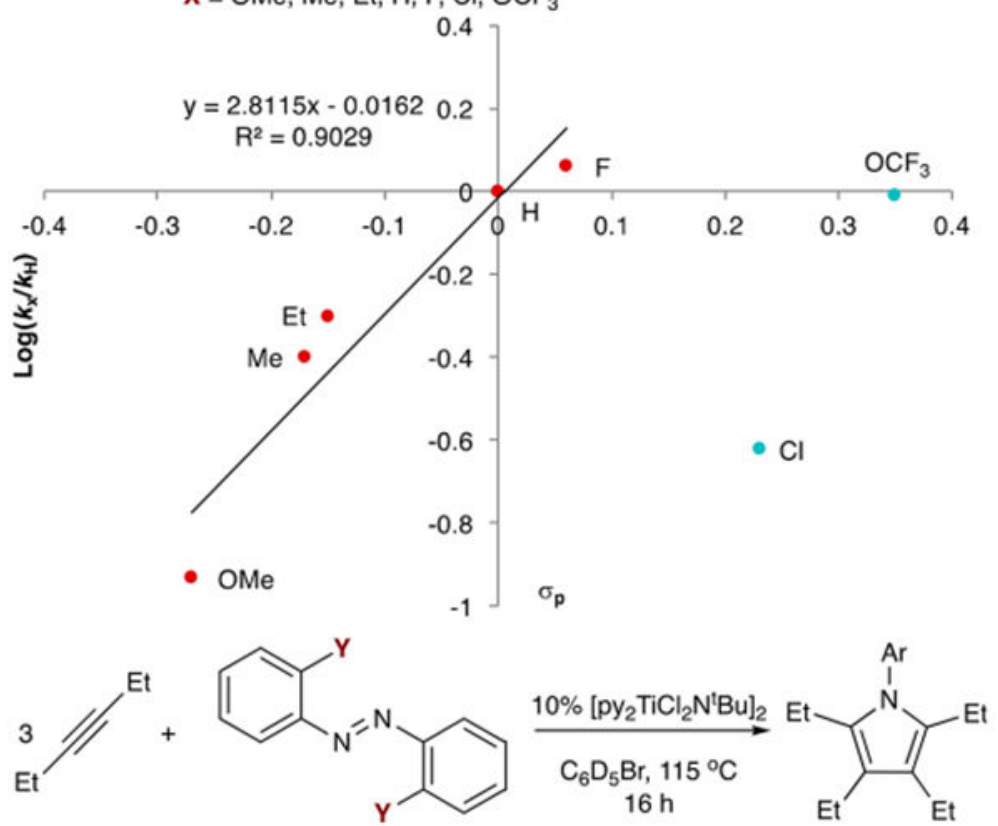

$\mathrm{Y}={ }^{\mathrm{P}} \mathrm{Pr}, \mathrm{Et}, \mathrm{Me}, \mathrm{H}$

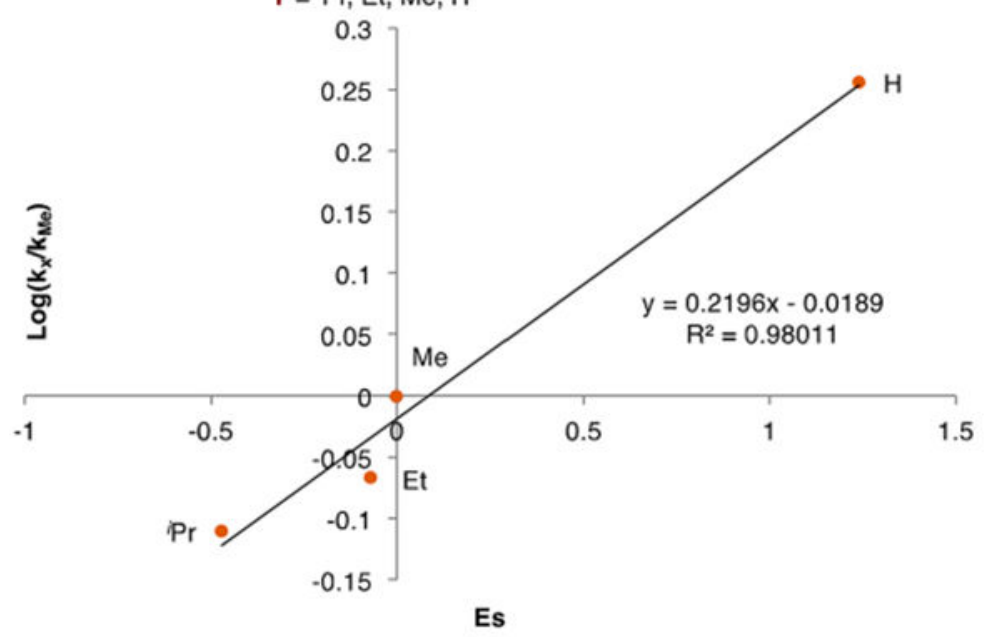

Figure 17.

Hammett (top) and Taft (bottom) plots of substituted diazenes. Reaction conditions can be found in Table S4. 
Table 1.

Occupation Number of the $3 \mathrm{dz}^{2}$ Orbital Compared with the Formal Oxidation State of the Ti Atom in the Complex $^{a}$

\begin{tabular}{|c|c|c|}
\hline Species & Occupation numbers ( $3 \mathrm{dz}^{2}$ orbital) & Formal Oxidation State \\
\hline IM1 & 0.31 & +4 \\
\hline IM2 & 0.30 & +4 \\
\hline TS1 & 0.35 & +4 \\
\hline IM3 & 0.38 & +4 \\
\hline IM4 & 0.37 & +4 \\
\hline TS2 & 0.40 & +4 \\
\hline IM5 & 0.44 & +4 \\
\hline TS3 & 0.54 & $+2 /+4$ \\
\hline IM6 & 0.61 & +2 \\
\hline IM7 & 0.72 & +2 \\
\hline IM8 & 0.38 & +4 \\
\hline $\mathbf{T i C l}_{2}$ & 0.82 & +2 \\
\hline$\left[\mathrm{TiCl}_{4}\right]^{2-}$ & 0.77 & +2 \\
\hline $\mathrm{TiCl}_{2} \mathbf{p y}_{2}$ & 0.68 & +2 \\
\hline $\mathrm{TiCl}_{2} \mathrm{py}_{4}$ & 0.65 & +2 \\
\hline $\mathrm{TiCL}_{4}$ & 0.29 & +4 \\
\hline
\end{tabular}

${ }^{a}$ Species labels match with structures in Figure 5. This analysis suggests that complexes with an occupation number closer to 0.4 should be assigned the formal +4 state and complexes with an occupation number closer to 0.6 should be assigned the form +2 state. 
Table 2.

Alkyne Substituent Effects on the Rate of $[2+2+1]$ Pyrrole Synthesis $^{a}$

\begin{tabular}{|c|c|c|c|c|c|}
\hline \multicolumn{2}{|c|}{ 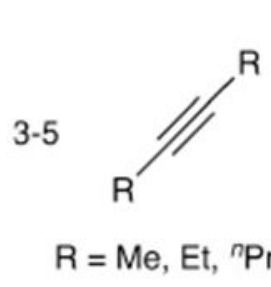 } & \multicolumn{3}{|c|}{ 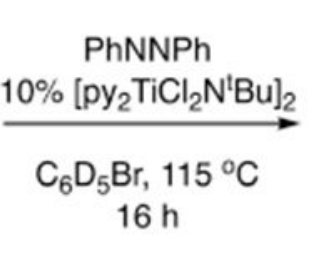 } & $\begin{array}{c}\mathrm{Ph} \\
\mathrm{I} \\
\mathrm{N}\end{array}$ \\
\hline $\mathbf{R}=$ & $k_{\mathrm{obs}} \times 10^{5}$ & $A^{b}$ & $E_{S}^{c}$ & $E_{R}^{d}$ & 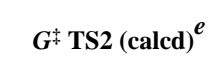 \\
\hline $\mathrm{Me}$ & & 1.7 & 0 & 17 & 29.1 \\
\hline $\mathrm{Et}$ & $5.97 \pm 0.4$ & 2.1 & 0.08 & 34 & 27.1 \\
\hline${ }^{n} \mathrm{Pr}$ & $0.980 \pm 0.07$ & 2.1 & 0.31 & 36 & 28.5 \\
\hline
\end{tabular}

Et vs ${ }^{n_{\operatorname{Pr}} \Delta \Delta^{+}}$from $k_{\text {obs }}: 1.4 \mathrm{kcal} / \mathrm{Et}$ vs ${ }^{n_{\operatorname{Pr}} \Delta \Delta^{+}}$from calcs: $1.4 \mathrm{kcal} / \mathrm{mol} \mathrm{mol}$

${ }^{a}$ Reaction conditions can be found in the Supporting Information. Et $=\mathrm{S} 43, \mathrm{Pr}=\mathrm{S} 64$.

$b_{\text {Steric } A \text { value. }}{ }^{50}$

$c_{\text {Taft steric parameter. }}{ }^{49}$

${ }^{d}$ Steric value. ${ }^{49}$

${ }^{e}$ M06/6-311g(d,p)/SMD/ultrafine grid in $\mathrm{C}_{6} \mathrm{H}_{5} \mathrm{Br} . \Delta G^{\dagger} \mathrm{TS} 2$ is the energy difference between CAT and TS2. 
Table 3.

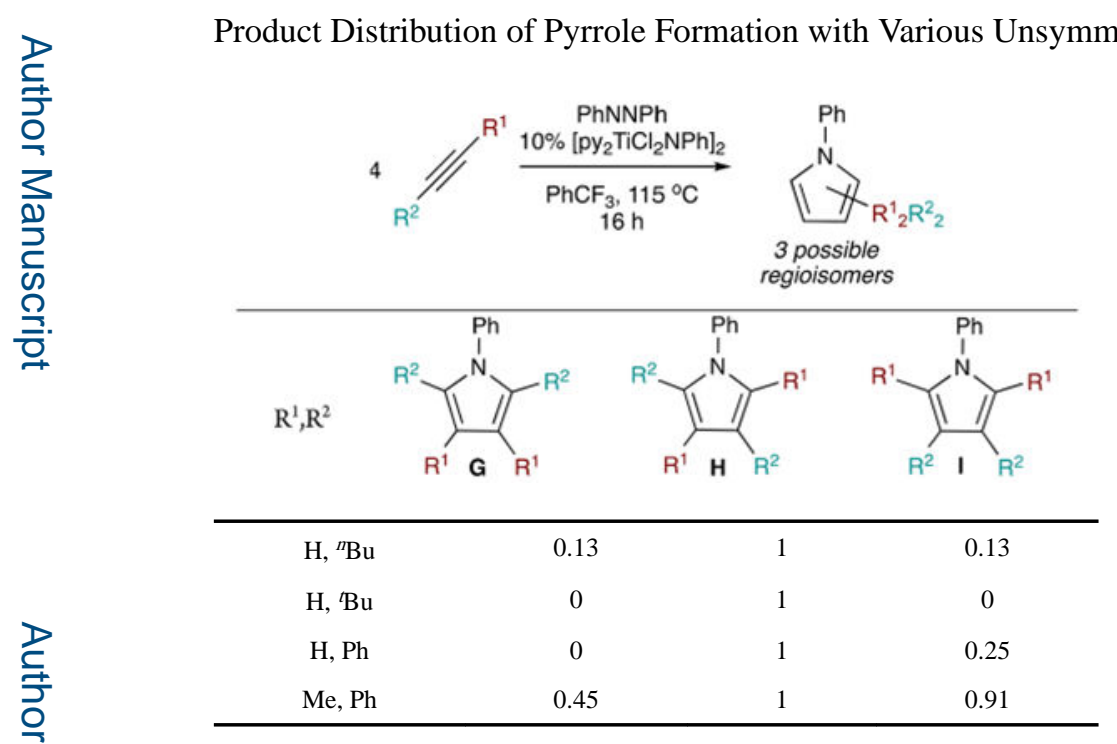

${ }^{a}$ Taken from ref 6. Copyright 2015 Nature Publishing Group. 
Table 4.

Ligand Donor Parameter (LDP) Effects on the Rate of $\mathrm{py}_{3} \mathrm{TiX}_{2} \mathrm{~N}^{t} \mathrm{Bu}$-Catalyzed Pyrrole Formation from 3Hexyne and Azobenzene ${ }^{a}$

\begin{tabular}{|c|c|c|}
\hline $\begin{array}{c}3 \\
\mathrm{Et}^{\prime}\end{array}$ & $\begin{array}{c}\text { PhNNPh } \\
10 \% \text { Catalyst } \\
\begin{array}{c}\mathrm{C}_{6} \mathrm{D}_{5} \mathrm{Br}, 115{ }^{\circ} \mathrm{C} \\
16 \mathrm{~h}\end{array}\end{array}$ & Et \\
\hline catalyst & $k_{\text {obs }} \times 10^{5}$ & $\%$ BurV $^{c}$ \\
\hline $\mathrm{py}_{3} \mathrm{TiCl}_{2} \mathrm{~N}^{t} \mathrm{Bu}$ & $0.42 \pm 0.17$ & 15.05 \\
\hline $\mathrm{py}_{3} \mathrm{TiBr}_{2} \mathrm{~N}^{t} \mathrm{Bu}$ & $0.97 \pm 0.17$ & 15.45 \\
\hline $\mathrm{py}_{3} \mathrm{TiI}_{2} \mathrm{~N}^{t} \mathrm{Bu}$ & $2.34 \pm 0.11$ & 15.80 \\
\hline$\left[\mathrm{py}_{2} \mathrm{TiCl}_{2} \mathrm{~N}^{t} \mathrm{Bu}\right]_{2}$ & $5.97 \pm 0.4$ & 15.05 \\
\hline
\end{tabular}

a Reaction conditions can be found in Table S6.

$b_{\text {Ligand donar parameter. }}$ 53,54

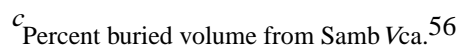


Table 5.

X-Type Ligand Effects on Product Distribution from Phenylpropyne ${ }^{a}$

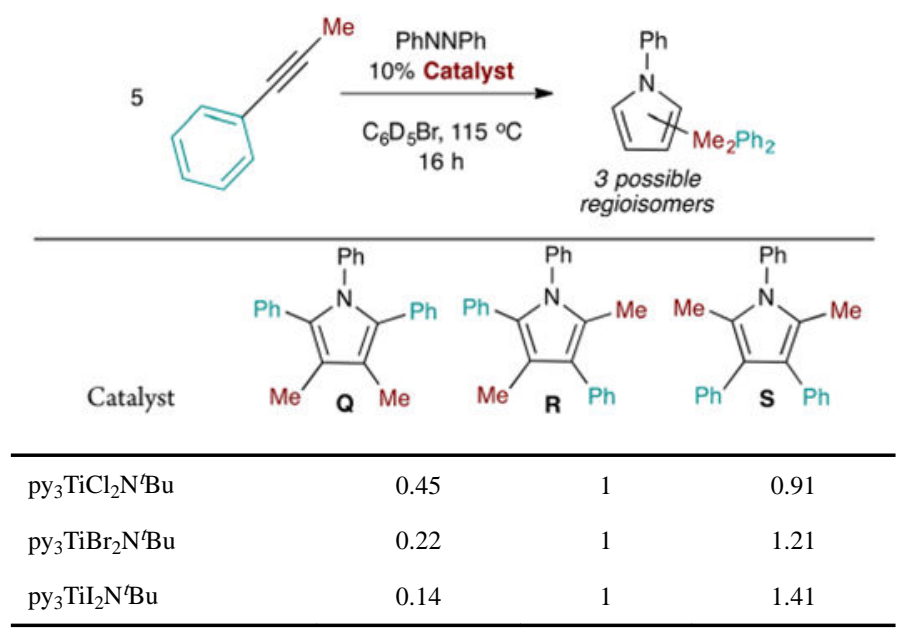

${ }^{a}$ All product ratios are standardized against $\mathbf{R}$. Reaction conditions can be found in Table S6. 